NBER WORKING PAPER SERIES

\title{
A REVEALED PREFERENCE RANKING OF U.S. COLLEGES AND UNIVERSITIES
}

\author{
Christopher Avery \\ Mark Glickman \\ Caroline Hoxby \\ Andrew Metrick \\ Working Paper 10803 \\ http://www.nber.org/papers/w10803 \\ NATIONAL BUREAU OF ECONOMIC RESEARCH \\ 1050 Massachusetts Avenue \\ Cambridge, MA 02138 \\ September 2004
}

The authors' affiliations are, respectively, John F. Kennedy School of Government at Harvard University; Department of Health Services at the Boston University School of Public Health, Department of Economics at Harvard University, and Department of Finance of The Wharton School at the University of Pennsylvania. We thank Bruce Sacerdote, Joel Waldfogel and seminar participants at Columbia, Wharton, Yale, the University of Texas at Austin, University of California Santa Cruz, Harvard, and the National Bureau of Economic Research for helpful comments. We thank Andrew Fairbanks and Jim Barker, who helped to design and implement the College Admissions Project survey. We also thank Michael Behnke, Larry Momo, Jay Matthews, and the 510 high school counselors who made the survey happen. We are grateful for the aid of many hard-working and perspicacious research assistants: Joshua Barro, James Carmichael, Rohit Chandwani, Michael Cuthbert, Suzanne Ko, Ilyana Kuziemko, Michael McNabb, Kathryn Markham, Emily Oster, Chris Park, Jenna Robins, Aaron Roth, Maria Shim, Catherine So, Rania Succar, Michael Thakur, Kenneth Wang, and Jill Zitnik. Scott Resnick deserves very special thanks. The first version of this paper appeared in October 2002. The views expressed herein are those of the author(s) and not necessarily those of the National Bureau of Economic Research.

(C2004 by Christopher Avery, Mark Glickman, Caroline Hoxby, and Andrew Metrick. All rights reserved. Short sections of text, not to exceed two paragraphs, may be quoted without explicit permission provided that full credit, including (C) notice, is given to the source. 
A Revealed Preference Ranking of U.S. Colleges and Universities

Christopher Avery, Mark Glickman, Caroline Hoxby, and Andrew Metrick

NBER Working Paper No. 10803

September 2004

JEL No. I2, C11, C25

\section{$\underline{\text { ABSTRACT }}$}

We show how to construct a ranking of U.S. undergraduate programs based on students' revealed preferences. We construct examples of national and regional rankings, using hand-collected data on 3,240 high- achieving students. Our statistical model extends models used for ranking players in tournaments, such as chess or tennis. When a student makes his matriculation decision among colleges that have admitted him, he chooses which college "wins" in head-to-head competition. The model exploits the information contained in thousands of these wins and losses. Our method produces a ranking that would be difficult for a college to manipulate. In contrast, it is easy to manipulate the matriculation rate and the admission rate, which are the common measures of preference that receive substantial weight in highly publicized college rating systems. If our ranking were used in place of these measures, the pressure on colleges to practice strategic admissions would be relieved.

Christopher Avery

Harvard University

John F. Kennedy School of Government

79 John F. Kennedy Street

Cambridge, MA 02138

and NBER

christopher_avery@ksg.harvard.edu

Mark Glickman

Department of Health Services

School of Public Health

Boston University

mg@math.bu.edu
Caroline Hoxby

Department of Economics

Harvard University

Cambridge, MA 02138

and NBER

choxby@harvard.edu

Andrew Metrick

The Wharton School

University of Pennsylvania

3620 Locust Walk

Philadelphia, PA 19104

and NBER

metrick@wharton.upenn.edu 


\section{Executive Summary}

We show how to construct a ranking of U.S. undergraduate programs based on how desirable students find them. We call this the revealed preference ranking of colleges. We construct examples of national and regional rankings, using data we collected on the college applications, admissions, and matriculation of 3,240 high- achieving students.

Our statistical model extends models used for ranking players in tournaments, such as chess or tennis. When a student decides to matriculate at one college, among those that have admitted him, he effectively decides which college "won" in head-to-head competition. The model efficiently combines the information contained in thousands of these wins and losses.

Our method produces a ranking that would be very difficult for a college to manipulate. In contrast, colleges can easily manipulate the matriculation rate and the admission rate, which are the crude proxies commonly used to measure colleges' desirability. Because there is a strong demand for measures of colleges' desirability, colleges are forced to advertise their matriculation and admissions rates. Moreover, college guides like U.S. News are forced to give substantial weight to the matriculation and admissions rates. These crude proxies are not only misleading; they induce colleges to engage in distorted conduct that decreases the colleges' real selectivity while increasing the colleges' apparent desirability. So long as colleges are judged based on their crude admissions and matriculation rates, they are unlikely to eliminate strategic admissions or roll back early decision programs, which are the key methods of manipulating the proxies. Many college administrators correctly perceive that they are in a bad equilibrium. Yet, so long as the crude proxies are used, the bad equilibrium is likely to persist. If our ranking method were used, the pressure on colleges to practice strategic admissions would be relieved.

We rank more than 100 colleges in the national ranking, and we show how each college is likely to fare in a head-to-head match up against specific rival colleges. We also show regional rankings and demonstrate that they combine up to generate a truly national ranking among colleges that are highly preferred. We explain how to think about niche colleges, such as California Institute of Technology, whose applicants are self-selected to an unusual degree; and we propose useful sub-rankings for certain types of colleges. 


\section{Why a Revealed Preference Ranking?}

In this study, we show how to construct a ranking of U.S. undergraduate programs based on students' revealed preferences -that is, the colleges students prefer when they can choose among them. The result is a ranking of colleges based on their desirability. We develop a statistical model that logically extends models used for ranking players in tournaments, such as chess and tennis. When a student makes his matriculation decision among colleges that have admitted him, he chooses which college "wins" in head-to-head competition. The model exploits the information contained in thousands of these wins and losses.

We construct an example of our ranking using data from a survey of 3,240 highly meritorious students that was specifically conducted for this study. Because we do not have a fully representative sample of college applicants, we rank only about a hundred undergraduate programs and our ranking is an example, not definitive. Nevertheless, we can show that our ranking has advantages. In particular, it is less manipulable than crude measures of revealed preference, such as the admissions rate and matriculation rate. A ranking constructed according to our method would be a good substitute for the preference indicators that receive substantial weight in formulas of high publicized college rating systems, like that of U.S. News and World Report. Many colleges currently feel compelled to engage in strategic admissions behavior in order to maximize their published college ratings. Use of our ranking method would relieve this pressure.

Rankings based on students' revealed preference measure a college's desirability in students' eyes. Such desirability may reflect a college's quality, but it is unlikely to be identical to quality. Indeed, the notion of what constitutes quality in a college is likely to differ from person to person. Faculty, parents, policy makers, and students may all assign different weights to colleges' characteristics. Why then construct a revealed preference ranking at all, which merely shows the value that students (in combination with their parents) put on colleges?

The primary reason that we are motivated to construct a revealed preference ranking is a practical one. Parents and students demand revealed preference information and college 
guides feel obliged to offer them some. The two measures of preference used by college guides are the crude matriculation rate and crude admissions rate. One objection to these measures is that they are inefficiently coarse. Our revealed preference ranking efficiently aggregates the information contained in individual students' decisions. Another serious objection to these measures is that colleges can manipulate them, though at a cost. Colleges do not necessarily want to manipulate their matriculation rate and admissions rate; they feel compelled to do so. A college that does not manipulate these rates, when its competitors do, loses ground in highly publicized college ratings. Such lost ground will eventually have real effects on the college's ability to recruit students, attract donations, and so on. ${ }^{1}$ In short, U.S. colleges are in a bad equilibrium: colleges manipulate the rates even though they would all be better off if no college manipulated the rates. If a revealed preference ranking like ours were used, colleges would find it extremely hard to "defect" and the bad equilibrium would not arise. All parties (including the college guides) should be pleased to have a measure of revealed preference that limits or even eliminates manipulation.

We have attempted to justify constructing a good indicator of revealed preference by pointing out that one is demanded. But, why do students and their parents demand such measures? There are a few possible answers.

First, students believe and act as though their peers matter. This may be because peer quality affects the level of teaching that is offered. Alternatively, students may learn directly from their peers. If such channels for peer effects are important, then it is reasonable for students to care about whether they are surrounded by peers with high college aptitude. Students will want to see a revealed preference ranking because it will show them which colleges can offer the highest concentration of desirable peers. A more preferred college wins more often in matriculation tournaments. Thus, it can afford to be more selective and can offer peers with higher aptitude.

Second, students-especially the high achieving students on whom we focus-are not

1 See evidence on the real effects of the ratings, see Ehrenberg and Monks (1999). 
ignorant about college quality. They gather information about colleges' quality from publications, older siblings, friends who are attending college, college counselors, and their own visits to colleges. A student may place the greatest weight on his own observations of quality, but he will also put some weight on the observations of other students, simply because his own sample of observations is too small to be representative. A revealed preference ranking efficiently aggregates observations about quality from thousands of students. There are parallels to other industries. For instance, people judge restaurant and hotel quality based partly on their own experiences, but they also want to know about other people's experiences. This is why there is a demand for guides like Zagat's, which aggregate people's observations about hotels and restaurants.

Third, it has long been hypothesized that specific colleges' degrees serve as signals of a student's aptitude, which is hard for future employers to observe directly [Spence, 1974]. In equilibrium, a college's degree signals the aptitude of the students who actually attend it. For instance, there will be an equilibrium only if a Princeton degree signals aptitude that is consistent with the actual distribution of aptitude among Princeton students. This is another reason for students to care about the ability of their peers and, thus, their college's tendency to attract students. $^{2}$

In Section II of the paper, we further discuss the weaknesses of using the matriculation rate and the admissions rate as measures of revealed preference, and show how these measures can easily be manipulated. In Section III, we present our statistical model of college choice as a multiple comparison problem. We show how to account for the potentially confounding effects of tuition discounts, financial aid, and other factors that might make a college "win" when it would lose on the basis of its intrinsic desirability.

The data for our study was hand-collected in a survey of 510 high schools, with surveys

${ }^{2}$ We do not know, however, that such signaling is actually important. Students may be able to use indicators other than their college degrees to inform future employers about their abilities. For instance, a student whose abilities much exceed those of his college classmates could reveal his very high grades, his leadership, his ability to win national fellowships, and so on. 
returned for 3,240 students. Section IV describes the survey methodology and provides summary statistics for the sample. These data are used to estimate the model, with the results discussed in Section V. Section VI concludes the paper.

\section{The Manipulability of Various Measures of Revealed Preference}

One of the two common measures of revealed preference is the matriculation rate-the share of accepted students who matriculate at a college:

$\frac{\text { number of students who matriculate }}{\text { number of students who are admitted }}$.

There are several methods by which a college can manipulate its matriculation rate. The reason that most methods work is that the matriculation rate is just an aggregate statistic and has no way of taking account of the composition of the pool of admittees (higher or lower merit?) and or of which students within the pool of admittees are matriculating (those with the best alternative offers or those with worst alternative offers?).

An early decision program is the most dramatic means by which a college can manipulate its matriculation rate. Every early decision admittee has a 100 percent probability of matriculating, so -mechanically- the more students whom a college admits under its early decision program, the higher is its matriculation rate. (It is important to distinguish between early decision, in which a student commits to matriculate if admitted, and early action, in which a student is admitted early but can apply to numerous other colleges and turn down the early admission offer.) An early decision program is not without costs for the college. As Avery, Fairbanks, and Zeckhauser (2003) show, college lowers their admissions standards for early decision applicants in order to induce them to pre-commit to matriculating and pre-commit to having no alternative offers when it comes to negotiating over financial aid. As a college admits more and more of its class under early decision, its actual admissions standards fall and students will therefore experience less meritorious peers. Yet, by the standard of the matriculation rate, the college's desirability will have risen.

Another method by which a college can manipulate its matriculation rate is deliberately 
not admitting students who are likely to be admitted by close competitors or colleges that are often more highly preferred. A college administrator may say to himself, "My college will ultimately fail to attract good applicants unless I raise its matriculation rate. I can achieve this with a strategic policy that denies admission to students who seem likely to be accepted by colleges more desirable than mine. By systemically denying them admission, my college will of course lose of its some most desirable students (because some percentage of the highly desirable students would have matriculated). However, it is worthwhile to sacrifice the actual desirability of my college class in order to appear more desirable on a flawed indicator." To make this strategy concrete, suppose that Princeton wanted to raise its matriculation rate. It could decide to admit only students who were very likely to fall just short of the admissions thresholds for Harvard, Yale, Stanford, MIT, and other close competitors. The students admitted would thus have no colleges in their "menus" that were close competitors to Princeton, and they would be likely to matriculate. Students who attend Princeton would almost certainly prefer that the university not pursue such a policy because it would reduce the peer quality of their fellow students. Yet, by the standard of the matriculation rate, Princeton's measured appeal would rise just as its actual appeal fell.

We have not arbitrarily selected Princeton for our example. It is by no means alone in appearing to practice somewhat strategic admissions (for other examples, see "Glass Floor: How Colleges Reject the Top Applicants and Boost Their Status," 2001), but it makes for a particularly clear example in our data. ${ }^{3}$ Consider Figure 1, which shows admissions at Harvard, MIT, and Princeton. If a college is not practicing strategic admissions, then the probability that a student is admitted ought to rise monotonically in his or her merit. In contrast, a college that is strategic will have non-monotonic admissions probabilities. A student's probability of admission will first rise in his or her merit and then fall as his or her merit moves into the range in which the strategic college faces stiff competition. In other

\footnotetext{
3 As described below, we have the most ample data on the colleges that are the most selective. Princeton provides the clearest example among the top several such colleges.
} 
words, the college will avoid admitting students in the range in which it is likely to lose in a matriculation tournament. Finally, if the student's merit is high enough, a strategic college will probably admit the student even if the competition will be stiff. This is because the prospective gains from enrolling a "star" will more than make up for the prospective losses from a higher

Figure 1

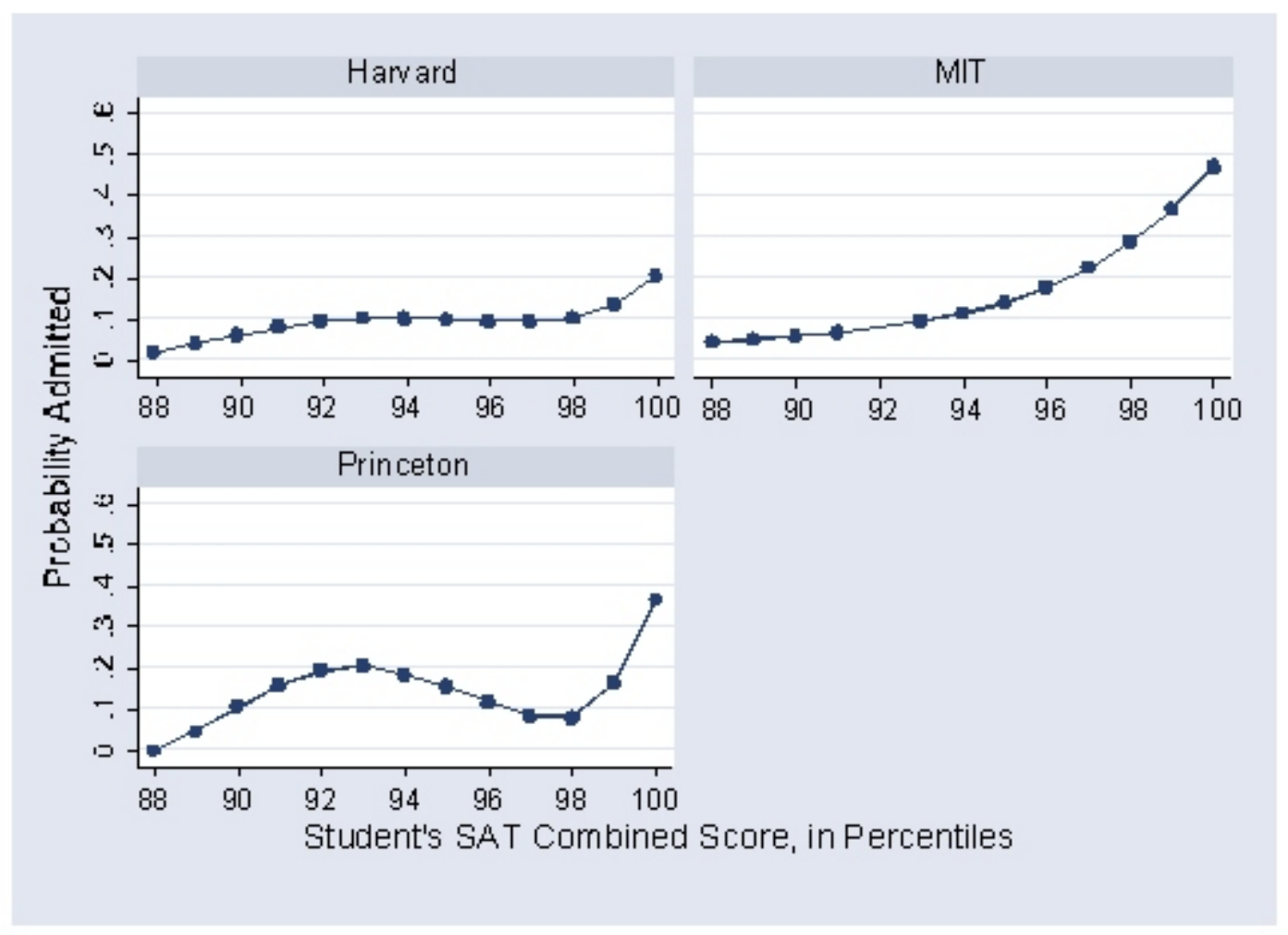

admissions rate and lower matriculation rate. (Recall that the crude admissions rate and matriculation rate do not record who is admitted or matriculates.)

Although we realize that it is not a definitive measure of a student's merit, for the sake of these purely illustrative figures, we use a student's combined SAT I score, measured in national percentiles. This measure is at least readily understood and reasonably continuous. It is also wholly unrelated to our ranking method.

Examine MIT admissions in Figure 1. The probability of a student's being admitted 
rises steeply and monotonically in his or her combined SAT score, suggesting that MIT is not engaging in strategic admissions. Now examine Harvard admissions in Figure 1. The line has a flat region that suggests that the probability of a student's being admitted is about 10 percent regardless of where his SAT scores in the range between the 93rd and the 98th percentiles. Above the 98th percentile, a student's probability of admissions rises steeply. Finally, consider Princeton admissions in Figure 1. At Princeton, the admissions probability rises to 20 percent at the 93 percentile, then falls to 10 percent at the 98 percentile (precisely the region where competition is toughest), and then rises again for students with SAT scores in the top 2 percentiles.

In short, it appears that Princeton practices more strategic admissions than MIT or Harvard. When we see the revealed preference ranking later in the paper, we will see that Figure 1 makes sense because Harvard and MIT could benefit less from strategic admissions than Princeton could. While Figure 1 is not definitive, it provides suggestive evidence that even a highly prestigious school may practice potentially costly strategic admissions. Such behavior is potentially costly to the actual quality of an admissions class, with no clear benefit beyond a higher reported matriculation rate.

The second of the two common proxies for revealed preference is the admission rate-that is, the share of applicants who are admitted by a college:

$$
\frac{\text { number of students who are admitted }}{\text { number of students who apply }} \text {. }
$$

There a several methods by which a college can manipulate its admissions rate. The reason that most methods work is that the admissions rate is just an aggregate statistic. It does not account for the composition of the pool of applicants (are they high or low merit?). It does not account for which applicants a college admits.

In forming a class of a given size, a college can admit fewer students if its matriculation rate is higher. Therefore, the methods discussed above for manipulating the matriculation rate are also methods for manipulating the admissions rate. For instance, if a college makes heavy use of an early decision program, it only needs to admit only slightly more students than the 
number that it actually wishes to enroll. This is because the early decision admittees are precommitted to enrolling. The technique of not admitting applicants who are likely to be admitted by close competitors also allows a college to publish a lower (better) admissions rate.

In addition, colleges can manipulate their admissions rate by encouraging applications from students who have little chance of actually gaining admission. A college can advertise less stringent criteria than it actually applies. By doing so, it encourages marginal students to apply, increases its number of applications, decreases its admissions rate, and raises its apparent desirability, even though its real desirability has not changed. For instance, this is how Toor (2000) described her job as an admissions officer at Duke University: "The job of admissions officers is to recruit, to boost application numbers. The more applications, the lower the admit rate, the higher the institutional ranking. Increasing application numbers is usually the No. 1 mandate of the recruiting season. Partly, that means trying to get the very best students to apply. But it also means trying to persuade those regular, old Bright Well-Rounded Kids (B.W.R.K.'s, in admissionese) to apply -- so that the college can reject them and bolster its selectivity rating."

In short, the two conventional measures are manipulable by colleges, though at a cost. If the goal of college admissions is to admit the optimal class, then colleges must systemically deviate from this goal in order to manipulate their matriculation and admissions rates. Colleges must sacrifice actual desirability for apparent desirability. Even if all colleges prefer not to manipulate the crude rates, each college will lose if it refrains from manipulation when other colleges do not refrain.

How might colleges escape this bad equilibrium? If the measure of revealed preference is not manipulable (or manipulable only by very complex, costly means), then all parties could be better off. In the next section, we formally describe the statistical method we use to create a revealed preference ranking of colleges. Here, we can give some intuition into why a ranking based on our method is not prey to simple forms of manipulation. For this exercise, it may be helpful for readers to think of some sport or game familiar to them.

Our method is based on "wins" and "losses" in thousands of "tournaments" in which 
students are choosing the college at which to matriculate. Under this method, a college's ranking vis-a-vis a competitor is based on its record of wins and losses. Colleges that rarely compete directly in tournaments (because they are of very different selectivity) are ranked using the win/loss records of intermediate colleges that link them through series of tournaments: A routinely competes with B, B routinely competes with $\mathrm{C}, \mathrm{C}$ routinely competes with D, etc. Given our methods, there is no easy way for a college to artificially boost its ranking with no true change in its appeal to students. For instance, recall the example in which Princeton alters its acceptance decisions in order to avoid match-ups with Harvard, Yale, Stanford and so on. We would be unable to rank Princeton rank vis-a-vis its close competitors because its match-ups would always be against less selective colleges. That is, our estimates would reflect the fact that Princeton was not admitting the highly meritorious students for whom it should have been competing. We would see that, while it was consistently "winning," it was winning only among students who failed to get admitted to close competitors.

Readers might also find it helpful if we stated what a college would need to do if it were to manipulate our ranking successfully. None of the crude methods of manipulation described above would work. A college would need to do something more subtle. Return to the Princeton example, for concreteness. Princeton would need to find students in its applicant pool who were likely to attend Princeton even if admitted to Harvard, Yale, MIT, Stanford, and so on. Such students would have to exist exogenously; they could not be "created" by Princeton's giving them extra aid to induce them to matriculate. (Giving them extra aid would not work because we can observe and account for aid.) Moreover, Princeton would have to identify these students using characteristics not observable to other colleges. If the trait that Princeton used to pick out likely matriculators was observable (such as being a Princeton alumnus' child), then this trait could be used as a control in any revealed preference ranking, as we will do below with some characteristics collected in our study. Without an early decision program to bind students or "secret" traits that distinguished its likely matriculators, a college could not identify students whose matriculation tournaments it would win. 


\section{The Model}

\section{A. The Desirability of Colleges}

The exercise of ranking colleges is necessarily predicated on the notion that there are latent indices of desirability on which college can be ranked. In the language of econometrics, the exercise is based on the assumption there are latent variables that indicate the desirability of each college (perhaps on multiple dimensions). Our measure of desirability encompasses all characteristics of a school, including (perceived) educational quality, campus location, and tuition. We do not claim to know how latent desirability is constructed. We simply assert that, to the extent that students act in accordance with it, we can construct rankings.

We suspect that latent desirability is well defined on a national basis for the most academically elite colleges in the United States. We also suspect that latent desirability is defined on a national basis for the most elite specialized colleges in the United States: engineering schools, music schools, and so on. We would not be surprised to find, however, that once we move below the most academically elite colleges, latent desirability is only welldefined within regions of the country and perhaps within other dimensions. If we had a very large, random sample of all college applicants, we could construct rankings within regions and specialties and show where they joined up to become a national ranking. Given that the data we use for our exercise is focused on high achieving students who do not apply much outside the group of the most academically elite colleges, we will start by constructing a national ranking of such colleges. We will rank only those that the data suggest have a national draw. Subsequently, we construct regional rankings and discuss specialized rankings. Until then, however, we encourage the reader to think of a college's latent desirability as being unidimensional.

For our exercise, is it necessary that all students identically perceive a college's desirability? No. We will allow students' perception of a college's desirability to be distributed around a mean level. Indeed, if there were no such distributions, all students would make identical matriculation decisions when offered the same choices. We know that this does not 
occur. What we need for our exercise is a pattern of wins and losses that would arise if colleges had latent desirabilities that were perceived with idiosyncratic noise added in.

Finally, note that our exercise does not impose the existence of latent desirability; our method simply will not work if widespread agreement on desirability does not exist. To see this, suppose that there were no uniformity in how students perceived colleges' desirability. Each student would act as though he had been randomly assigned a ranking of colleges, where his ranking was independent of all other students' rankings. We would find no pattern in the "wins" and "losses" because it would be random whether a college won or lost in head-to-head competition for a student. Overall, we can afford to be agnostic about how students develop preferences over colleges. Our data will only reveal such preferences to the extent that they are systematic.

The problem of ranking colleges can be framed as a collection of multiple comparisons. Comparison data come from competitions in which alternatives are compared and an outcome indicates that one alternative has been preferred over the others. Many sports and games fall into this framework because players are compared via competition, and the winner of a competition is deemed the "preferred alternative." Also, marketing applications, including experiments in which consumers choose among products or services, are well-suited to multiple comparison models. An important problem addressed by multiple comparison models is how to rank objects when direct comparisons do not take place. For example, in the context of a "Swiss system" chess tournament, every competitor competes against only a few other individuals rather than against every other competitor. That is, player A competes against $B$, and $B$ competes against $C$, but $A$ does not compete against $C$. Yet, an inference is still desired for the comparison of A versus C. In the context of college choice, every college does not compete directly with every other college, though the goal is to draw conclusions about all colleges' desirability.

\section{B. Matriculation Tournaments as a Multiple Comparison Problem}

To understand how college choice can be viewed as a multiple comparison problem, suppose that a collection of students has been admitted to a set of schools. Each schools' 
desirability is modeled as a latent distribution of values. Each student effectively holds a tournament among the collection of schools that have admitted him; in our model this tournament is played by taking one draw from each school's distribution. The school with the highest draw has "won" the multi-player tournament, and the student matriculates at that school. Assuming that there are no confounding variables, a reasonable inference is that the school that wins the multi-player tournament is preferred to the other schools in that competition. By aggregating the information from all students' tournaments, inferences about the desirability of schools can be constructed.

David (1988) surveys the rich body of work on multiple comparison modeling, which mainly focuses on paired comparison models, where each tournament contains only two players. While no one has previously attempted to rank colleges using comparison models, there are abundant applications for divining chess ability from tournament data-- see, for example, Zermelo (1929), Good (1955), Elo (1978) and Glickman (1993, 1999, 2001).

We build on the Bradley-Terry (1952) and the Luce (1959) models in which the distribution of desirability is an extreme value distribution. The assumption of an extreme value distribution for potentially observed desirability leads to a logit model. The main alternative to the assumption of an extreme value distribution for potentially observed desirability is a normal distribution. This leads to a class of models studied by Thurstone (1927) and Mosteller (1951) in the context of paired comparisons. When analyzing paired comparison data in practice, it makes almost no difference whether one assumes that the distribution of potentially observed desirability is extreme value or normal (see Stern, 1992). Models based on extreme value distributions tend to be more tractable and computationally efficient, which guides our choice.

It is worth noting that the extreme-value or normal distribution of potential desirabilities is a probabilistic assumption about the merit of an individual school, not an

\footnotetext{
${ }^{4}$ Statistical comparison models have also been used to study which college characteristics students like and which student characteristics colleges like. See, for example, Manski and Wise (1983), Long (2003), Avery and Hoxby (2004).
} 
assumption about the distribution of mean desirabilities across schools. Because college comparison data can provide strong information about the relative desirabilities of colleges, any assumptions made about the distribution of mean desirabilities should be weak. Our modeling approach allows for the possibility, for example, that a small number of schools are estimated to have mean desirabilities substantially greater than the remaining schools considered.

\section{The Matriculation Model}

Assuming that each college's potentially observed desirability follows an extreme value distribution with the same scale and shape, the relevant parameter is the location parameter of the distribution. The latent variable is:

$$
\theta_{i}=\text { the desirability parameter of college } i,
$$

where we index colleges with $i=1,2, \ldots, I$.

Students prefer colleges with higher desirability, among those in their choice set. Suppose that student $j$ is admitted to a set of colleges $s_{j}$ consisting of $m_{j}$ schools. Let the indicator variable $Y_{i j}$ tell us which college the student chooses:

$$
Y_{i j}=\left\{\begin{array}{ll}
1 & \text { if student } j \text { matriculates at college } i \\
0 & \text { otherwise }
\end{array}\right\} .
$$

The result of the multi-player competition among the $m_{j}$ colleges that admitted student $j$ is assumed to follow a multinomial distribution:

$$
\left(Y_{1 j}, \ldots, Y_{m_{j} j}\right) \sim \text { Multinomial }\left(1,\left(p_{1 j}, \ldots, p_{m_{j}}\right)\right),
$$

where $p_{i j}$ is the probability that student $j$ chooses to matriculate at college $i$ among his $m_{j}$ college choices. ${ }^{5}$ We assume Luce's choice model, of the form:

$$
p_{i^{*} j}=\frac{\exp \left(\theta_{i^{*}}\right)}{\sum_{i \in S_{j}} \exp \left(\theta_{i}\right)}, \quad i^{*} \in S_{j} .
$$

${ }^{5}$ For expositional convenience, we have reindexed the colleges in student $j$ set $S_{j}$, so that they can be written $1, \ldots, m_{j}$. 
This model can be rewritten as a conditional logit model, sometimes called McFadden's choice model.

The $\theta_{i}$ s include all characteristics that do not vary within each college: such characteristics include average perceptions about the quality of the education and the average cost of attendance. For some characteristics, we can measure variation across applicants: tuition, room fees, board fees, grants to the student, the subsidy value of loans to the student, the subsidy value of the work-study it offers the student, the cost associated with its distance from the student's home, its being in-state, its being in-region, and its being the alma mater of one or more of the student's parents. We add these characteristics to the model to gain extra explanatory power. ${ }^{6}$

Let the vector $x_{i j}=\left(x_{1 i j}, x_{2 i j}, \ldots, x_{K i j}\right)^{\prime}$ be the $K$ characteristics that can vary among admittees and that are faced by admittee $j$ who is considering whether to matriculate at college $i$. Note well that each characteristic is de-meaned so that we obtain the college's desirability at its average level in the data. It is not possible to separately identify the effect of these average characteristics from the $\boldsymbol{\theta}_{i}$ for each school. We treat $\boldsymbol{x}_{\boldsymbol{i}}$ as a vector of covariates which are allowed to enter the model linearly. Specifically, the probabilities for the matriculation model become:

$$
p_{i^{*} j}=\frac{\exp \left(\theta_{i^{*}}+x_{i j}^{\prime} \delta\right)}{\sum_{i \in S_{j}} \exp \left(\theta_{i}+x_{i j}^{\prime} \delta\right)}, \quad i^{*} \in S_{j} .
$$

In fitting the model, not only are the $\theta_{i}$ inferred, but so are the $\delta$, which are the effects of the characteristics on matriculation.

\section{Self-Selection and the Application Decision}

We estimate the $\theta_{i}$ from matriculation decisions of admitted applicants. Of course, to be admitted, one must first apply, so our underlying data for each school is not a random sample of all students, but rather of all students conditional on their application to that school. This is a

${ }^{6}$ In practice, the covariates have a trivial effect on the rankings. Estimates of the model without covariates are available from the authors. 
self-selected group, and we expect a group of applicants to find a school more desirable than an otherwise identical set of non-applicants. Such self-selection does not induce any bias if the applicant pool for every school is shifted equivalently: that is, if we are estimating a $\boldsymbol{\theta}_{\boldsymbol{i}}$ for every school based on the applicant pool, but the equivalent parameter for all students (applicants and non-applicants) is $\theta_{i}-\alpha_{i}$, and the $\alpha_{i}$ is the same for all schools, $i$. Since our ratings are unique only up to a constant, such a shift would not change the interpretation of our results.

Self-selection would cause a problem if the applicant pools are induced differently across schools. This would appear to be a major issue only for "niche schools" that attract applications from only the most interested students. Any speciality school could fall into this category, with engineering schools, school with a religious affiliation, or single-sex schools being the most likely. These schools might attract applicant pools with stronger preferences because students who are lukewarm about the speciality don't bother to apply - and effectively have a higher $\alpha_{i}$, leading the estimated $\theta_{i}$ to be biased upward.

The ideal way to handle these selection issues would be to explicitly model the application decision, but this is not feasible without many further assumptions. With thousands of schools to choose from, even artificial constraints on the number of applications leads to a complex combinatorial problem. In this case, the modeler - like the applicants themselves - is forced to use shortcuts and assumptions. Since these assumptions would ultimately drive the extent of selection bias, it seems more straightforward to acknowledge this potential bias and discuss its implications where it is appropriate. Thus, we proceed under the baseline assumption that the $\alpha_{i}$ are identical across schools. In Section V, we discuss the implications of deviations from this assumption, point out specific schools for which these deviations may make a difference, and propose a practical method for dealing with them.

While we do not believe that self-selection is a major issue for the $\theta_{i}$ estimates, it is of greater concern for inference on the $\delta$ coefficients For instance, suppose that price sensitivity is heterogeneous and students who are especially price sensitive seek out colleges that offer them substantial discounts. We might overestimate the effects of prices because the variation in the data comes disproportionately from price-sensitive students. For this reason, we will not 
give strong interpretations to the coefficients on these characteristics. It is still useful to include these characteristics in the regression, especially because they may proxy for otherwise unobservable variables.

\section{E. Model Fitting}

The complexity of our model lends itself naturally to fitting the model in the Bayesian framework. We fit our model by computing the posterior distribution of model parameters followed by summarizing important features of the distribution. The posterior distribution of parameters is proportional to the product of the likelihood function with a prior distribution. The likelihood can be written as a product of multinomial logit probabilities derived from equation (6). We assume a locally uniform but proper prior distribution that factors into independent densities. The prior distribution consists of the following components:

$$
\begin{gathered}
\theta_{i} \sim N\left(0, \sigma^{2}\right) \\
\frac{1}{\sigma^{2}} \sim \operatorname{Gamma}(0.1,0.1) \\
\delta_{k} \sim N(0,100) \quad \text { for } k=1,2, \ldots, K
\end{gathered}
$$

where $\delta_{k}$ indexes the $k^{\text {th }}$ element of the vector delta.

We summarize estimated college desirability by computing the posterior modes of the $\theta_{i}$. These were carried out using a Newton-Raphson algorithm for multinomial logit models, as implemented in Stata. The posterior modes are presented in Tables 3, 5 and 6. We also fit the model using Markov chain Monte Carlo(MCMC) simulation from the posterior distribution to infer more complex quantities of interest. For example, to answer questions like "is there a meaningful distinction in desirability between the college ranked 15th and the college ranked 20th?" we cannot simply rely on comparing posterior modes. Instead, MCMC produces simulated values from the posterior distribution of model parameters. Thus, using MCMC simulation, pairs of values can be generated from the posterior distribution of $\left(\theta_{15}, \theta_{20}\right)$, and the probability that $\theta_{15}$ is greater than $\theta_{20}$ can be evaluated by computing the proportion of pairs in which $\theta_{15}$ is greater than $\theta_{20}$. An answer like 95 percent or more - analogous to a $95 \%$ 
significance test - tells us that the colleges are substantially more distinct than an answer like 55 percent.

The MCMC algorithm proceeds as follows. Initial values of all parameters are set to the prior mean values (though the initial values can be set arbitrarily). Then values are simulated from the conditional posterior distributions of each model parameter. This process is repeated until the distributions of values for individual parameters stabilize. The values simulated beyond this point can be viewed as coming from the posterior distribution. A recent example of MCMC methods applied to paired comparison models is Glickman (2001).

We implemented the MCMC algorithm using the program BUGS (Spiegelhalter et al., 1996). For each model, a burn-in period of 10,000 iterations was run, and parameter summaries were based on every 5th iteration of a subsequent 30,000 iterations. Based on trace plots from our data analyses, 10,000 iterations was sufficient to reach the stationary distribution. Every 5th iteration was sampled to reduce the autocorrelation in successive parameter draws. This process produced 6000 values per parameter on which to calculate parameter summaries. In Table 4, which shows pairwise match-ups for each college we rank, we display summaries based on MCMC draws from the posterior distribution.

\section{Data}

To construct an example of our revealed preference ranking, we use from the College Admissions Project survey, in which we surveyed high school seniors in the college graduating class of 2004. ${ }^{7}$ We designed the survey to gather data on students with very high college aptitude who are likely to gain admission to the colleges with a national or broad regional draw that are most appropriate for ranking. While such students are represented in surveys that attempt to be nationally representative, such as the National Educational Longitudinal Survey, they are a very small share of the population of American students. As a result, the number of such students is so small in typical surveys that their behavior cannot be analyzed,

\footnotetext{
7 See Avery and Hoxby [2000] for additional detail.
} 
even if the survey contains a large number of students. By focusing on students with very strong academic credentials, we end up with a sufficient number of tournaments among colleges with a national draw to construct a revealed preference ranking among them.

We reemphasize that we use the College Admissions Project data to construct an example of a revealed preference ranking. If we had had much greater resources, we would have surveyed a more fully representative sample of students in the United States. With more data, our national ranking would be more definitive, and we would be able to rank many more colleges (most of them in regional or specialized rankings, not the national ranking). At the end of this section, we describe the cut-offs we used to determine which colleges we could reasonably rank.

\section{A. Survey Design}

In order to find students who were appropriate candidates for the survey, we worked with counselors from 510 high schools around the United States. The high schools that were selected had a record of sending several students to selective colleges each year, and they were identified using published guides to secondary schools, such as Peterson's and the experience of admissions experts. Each counselor selected ten students at random from the top of his senior class as measured by grade point average. Counselors at public schools selected students at random from the top $10 \%$ of the senior class, while counselors at private schools (which tend to be smaller and have higher mean college aptitude) selected students at random from the top $20 \%$ of the senior class. ${ }^{8}$ The counselors distributed the surveys to students, collected the completed surveys, and returned them to us for coding. ${ }^{9}$ Students were tracked

8 The counselors were given detailed instructions for random sampling from the top 20,30, 40, or 50 students in the senior class depending on the size of the school. For example, a counselor from a public school with 157 students was asked to select 10 students at random from the top 20 students in the senior class, with the suggestion that the counselor select students ranked $\# 1,3,5,7,9,11,13,15,17$, and 19.

9 The exception was the parent survey, which parents mailed directly to us in an addressed, postage-paid envelope so that they would not have to give possibly sensitive financial information to the high school counselor. 
using a randomly assigned number; we never learned the names of the students who participated.

Survey participants completed two questionnaires over the course of the academic year. The first questionnaire was administered in January 2000. It asked for information on the student's background and college applications; the majority of these questions were taken directly from the Common Application, which is accepted by many colleges in place of their proprietary application forms. Each student listed up to ten colleges where he had applied, his test scores, and race. In addition, each student listed the colleges and graduate schools (if any) attended by each parent and the colleges (if any) attended by older siblings along with their expected graduation dates.

The second questionnaire was administered in May 2000 and asked for information about the student's admission outcomes, financial aid offers, scholarship offers, and matriculation decision. Each student listed their financial aid packages with the amounts offered in three categories: grants, loans, and Work Study. We obtained detailed information on grants and scholarships. On a third questionnaire distributed to a parent of each survey participant, we collected information on parents' income range (see Table 1 for the income categories.)

We matched the survey to colleges' administrative data on tuition, room and board, location, and other college characteristics. In all cases, the ultimate source for the administrative data was the college itself and the data were for the 2000-01 school year, which corresponds to the survey participants' freshmen year. ${ }^{10}$

The College Admissions Project survey produced a response rate of approximately 65\%, including full information for 3,240 students from 396 high schools. ${ }^{11}$ The final sample contains

10 See Avery and Hoxby [2004] for a complete description of administrative data sources.

11 The most common reasons for failure to return the survey were changes of high school administration, an illness contracted by the counselor, and other administrative problems that were unrelated to the college admissions outcomes of students who had been selected to participate. 
students from 43 states plus the District of Columbia. ${ }^{12}$ Although the sample was constructed to include students from every region of the country, it is intentionally representative of applicants to highly selective colleges and therefore non-representative of American high school students as a whole. Regions and states that produce a disproportionate share of the students who apply to selective colleges are given a weight in the sample that is approximately proportionate to their weight at very selective colleges, not their weight in the population of American high school students. Of course, all of the students in the sample have very strong academic records.

Because the students are drawn from schools that send several students to selective colleges each year (though not necessarily to very selective colleges), the students in the sample are probably slightly better informed than the typical high aptitude applicant. However, in other work [Avery and Hoxby, 2004], we have found that students who make it into the sample act very much like one another when they make college decisions, regardless of whether they come from more or less advantaged backgrounds. This suggests that a revealed preference ranking based on our sample may reflect slightly more information than one based on the typical applicant, but the difference in the information embodied in the ranking is probably small.

\section{B. Sample Statistics}

The summary statistics shown in Tables 1 and 2 demonstrate show the students in the sample are high achieving. The average (combined verbal and math) SAT score among participants was 1357, which put the average student in the sample at the 90th percentile of all SAT takers. ${ }^{13}$ About 5 percent of the students won a National Merit Scholarship; 20 percent of them won a portable outside scholarship; and 46 percent of them won a merit-based grant from

\footnotetext{
12 The states missing from the sample are Alaska, Delaware, Iowa, Mississippi, North Dakota, South Dakota, and West Virginia.

${ }^{13}$ We converted American College Test (ACT) scores to SAT scores using the cross-walk provided by The College Board. We converted all college admissions scores into national percentile scores using the national distribution of SAT scores for the freshman class of 2000-01.
} 
at least one college. 45 percent of the students attended private school, and their parents' income averaged $\$ 119,929$ in $1999 .{ }^{14}$ However, 76 percent of the sample had incomes below the cut-off where a family is considered for aid by selective private colleges, and 59 percent of the students applied for need-based financial aid. ${ }^{15}$

Table 1

Description of the Students in the College Admission Project Data

\begin{tabular}{lrrrr} 
& Mean & Std. Dev. Minimum & Maximum \\
Variable & 0.41 & 0.49 & 0.00 & 1.00 \\
Male & 0.73 & 0.44 & 0.00 & 1.00 \\
White, non-Hispanic & 0.04 & 0.18 & 0.00 & 1.00 \\
Black, non-Hispanic & 0.16 & 0.36 & 0.00 & 1.00 \\
Asian & 0.04 & 0.19 & 0.00 & 1.00 \\
Hispanic & 0.00 & 0.03 & 0.00 & 1.00 \\
Native American & 0.04 & 0.19 & 0.00 & 1.00 \\
Other race/ethnicity & 0.83 & 0.38 & 0.00 & 1.00 \\
Parents are married & 0.23 & 0.42 & 0.00 & 1.00 \\
Sibling(s) enrolled in college & 119,929 & 65,518 & 9,186 & 240,000 \\
Parents' income & 27,653 & 16,524 & 0 & 120,000 \\
Expected family contribution & 0.59 & 0.49 & 0.00 & 1.00 \\
Applied for financial aid? & 0.05 & 0.22 & 0.00 & 1.00 \\
National Merit Scholarship winner & 1357 & 139 & 780 & 1600 \\
Student's combined SAT score & 90.4 & 12.3 & 12.0 & 100.0 \\
Student's SAT score, in national percentiles & & & & \\
Median SAT score at most selective college & 86.4 & 10.4 & 33.5 & 98.0 \\
to which student was admitted & & & & 97.0 \\
Median SAT score at least selective college & 73.8 & 14.6 & 14.3 & 1.00 \\
to which student was admitted & 0.45 & 0.50 & 0.00 & \\
Student's high school was private & & & & \\
\hline
\end{tabular}

14 See Avery and Hoxby [2004] for descriptions of how the aid variables were hand checked and how some parents' income was estimated based on their Expected Family Contribution, a federal financial aid measure.

15 The cut-off was approximately $\$ 160,000$, but the actual cut-off depends on family circumstances. 
83 percent of the student's parents were currently married, and 23 percent of the students had at least one sibling currently enrolled in college. The racial composition of the survey participants was 73 percent white, 16 percent Asian, 3.5 percent black, and 3.8 percent Hispanic.

Looking at Table 2, which shows descriptive statistics on the colleges where the students applied, were admitted, and matriculated; we can see that the survey participants applied to a range of colleges that included "safety schools" (the mean college to which a student applied had a median SAT score 8.5 percentiles below the student's own). However, the participants also made ambitious applications: 47.5 percent of them applied to at least one Ivy League college.

Table 2

Description of the Colleges in the College Admission Project Data

\begin{tabular}{|c|c|c|c|c|c|c|}
\hline & \multicolumn{6}{|c|}{ Colleges at Which Students } \\
\hline & \multicolumn{2}{|c|}{ Applied } & \multicolumn{2}{|c|}{ Were Admitted } & \multicolumn{2}{|c|}{ Matricalated } \\
\hline Variable & Mean & $\begin{array}{l}\text { Std. } \\
\text { Dev. }\end{array}$ & Mean & $\begin{array}{l}\text { Std. } \\
\text { Dev. }\end{array}$ & Mean & $\begin{array}{r}\text { Std. } \\
\text { Dev. }\end{array}$ \\
\hline Matriculated at this college & 0.28 & 0.45 & 0.18 & 0.39 & 1.00 & 0.00 \\
\hline Admitted to this college & 1.00 & 0.00 & 0.66 & 0.47 & 1.00 & 0.00 \\
\hline Grants from this college & 2720 & 5870 & 1778 & 4933 & 4029 & 7051 \\
\hline Loans from this college & 641 & 2282 & 413 & 1856 & 1020 & 2722 \\
\hline Work study amount from this college & 172 & 593 & 111 & 483 & 296 & 768 \\
\hline Father is an alumnus of this college & 0.04 & 0.20 & 0.03 & 0.17 & 0.07 & 0.25 \\
\hline Mother is an alumna of this college & 0.03 & 0.17 & 0.02 & 0.14 & 0.04 & 0.19 \\
\hline Sibling attended or attends this college & 0.05 & 0.21 & 0.04 & 0.19 & 0.08 & 0.28 \\
\hline College is public & 0.3325 & 0.4711 & 0.2631 & 0.4403 & 0.2843 & 0.4512 \\
\hline $\begin{array}{l}\text { College's median SAT score, in } \\
\text { percentiles }\end{array}$ & 80.5947 & 12.5188 & 83.8816 & 12.0390 & 83.4215 & 12.5494 \\
\hline In-state tuition & 16435 & 9594 & 18181 & 9199 & 17432 & 9513 \\
\hline Out-of-state tuition & 19294 & 6191 & 20498 & 5891 & 19841 & 6371 \\
\hline Tuition that applies to this student & 17671 & 8492 & 19277 & 7965 & 18340 & 8599 \\
\hline College is in-state & 0.3270 & 0.4691 & 0.2666 & 0.4422 & 0.3368 & 0.4727 \\
\hline $\begin{array}{l}\text { Distance between student's high scho } \\
\text { and this college, in miles }\end{array}$ & 597 & 809 & 673 & 873 & 576 & 827 \\
\hline
\end{tabular}


We can see that the students made logical application decisions. The mean college to which they applied had a median SAT score at the $83^{\text {rd }}$ percentile; the mean college to which they were admitted had median SAT score at the $81^{\text {st }}$ percentile. This small difference suggests that the students aimed a little high in their applications, a procedure that is optimal. 66 percent of the colleges to which students were admitted were private, and their mean tuition was $\$ 17,671$. Notice that we show the colleges' in-state tuition, out-of-state tuition, and the tuition that actually applies to the students in the sample (in-state or out-of-state as appropriate).

The final column of Table 2 shows descriptive statistics for the colleges at which the students matriculated. They are more selective, on average, than the colleges to which the students were admitted: their median SAT score is at the $83.4^{\text {th }}$ percentile, as opposed to the $81^{\text {st }}$ percentile median SAT score of the colleges to which students were admitted. This makes sense because it implies that students included "safety schools" in their choice sets, but often did not matriculate at them. One measure of the unusual college aptitude of the survey participants is the list of colleges at which the largest numbers of participants enrolled. Seventeen institutions enrolled at least 50 students from the sample: Harvard, Yale, University of Pennsylvania, Stanford, Brown, Cornell, University of Virginia, Columbia, University of California-Berkeley, Northwestern, Princeton, Duke, University of Illinois, New York University, University of Michigan, Dartmouth, and Georgetown.

\section{Results}

We show a college in the national ranking if it was not a military academy and if, in our sample, it competed in matriculation tournaments in at least six of the nine regions of the U.S. 106 colleges met these criteria. The mean college shown in the national ranking competed in 73 matriculation tournaments, and the median college competed in 57. Admittedly, the six region cut-off is somewhat arbitrary, but we show regional rankings after showing the national rankings. The regional rankings pick up extra colleges. Please note that if a small college fails to appear in the rankings, one should not conclude that its ranking is below 106 or that it does 
not have a national draw. For a small college, our sample might fail to pick up enough applicants to include the college in the national ranking, even if its draw is national in character.

\section{A. National Ranking}

Table 3 presents the revealed preference ranking of colleges and universities with a national draw. For each college, we present its mean desirability among students. Keep in mind that Table 3 shows only an example of our ranking method. With more data, we would produce a more definitive ranking. The rankings are on an arbitrary numerical scale of value, Elo points, which are used in chess and other game rankings. The conversion multiplies the $\boldsymbol{\theta}_{\boldsymbol{i}} \mathrm{s}$ by 173 and then adds whatever number gives 2800 points to the highest ranked college. ${ }^{16}$ The following table contains rule-of-thumb relationships between point differences and probability of winning:

\begin{tabular}{cl}
\hline 400 & .919 \\
300 & .853 \\
200 & .758 \\
100 & .637 \\
50 & .569 \\
0 & .500 \\
-50 & .431 \\
-100 & .363 \\
-200 & .242 \\
-300 & .147 \\
-400 & .081 \\
\hline
\end{tabular}

Note that Elo point differences tell us only about the college versus its mean competitor. Put another way, attaching standard errors to the estimates in Table 3 would not be very useful

\footnotetext{
${ }^{16}$ We choose 2800 as the maximum number because this is approximately the rating for the highest-rated chess player in the world. We use the Elo scale because of its familiarity. In addition to serving as the main rating system for chess and many other board games, the Elo scale has also been used in a wide variety of sports. A partial list includes soccer (www.eloratings.net/), college football (www.usatoday.com/sports/sagarin/fbt01.htm), cricket (www.ultra-sports.com/Cricket/UC4/ UC4abselo.html), and racquetball (www.eqp.com/pubs/rb/PlayerRankByELO.asp).
} 
because they would not reliably indicate whether any two colleges' rankings were statistically distinct. This is because the statistical significance of the difference between any two colleges' ranks depends on the overlap between their two groups of admittees. For this reason, it is best to use Table 4 for head-to-head comparisons between colleges.

Table 4 summarizes the results of posterior draws: the Bayesian analogue to a set of paired significance tests. For instance, in 96 percent of the draws from the posterior distribution, Harvard's ranking was higher than Yale's, and for 95 percent of the draws Harvard was higher than Cal Tech. For all other colleges, Harvard's ranking was higher in at least 99 percent of the draws. Put another way, we are 96 percent confident that Harvard's ranking is higher than Yale's, 95 percent confident it is higher than Cal Tech, and at least 99 percent confident that it is higher than that of other colleges. For Yale, in turn, we are 88 percent confident that its ranking is higher than Stanford's, 78 percent confident that its ranking is higher than Cal Tech's, and 91 percent confident that its ranking is higher than MIT's.

Table 4 helps us to understand the results for Cal Tech, which are somewhat problematic. Because students self-select into applying to Cal Tech based on an orientation toward math and science, Cal Tech's pool of admittees overlaps only slightly with that of most other institutions, except for MIT, with which Cal Tech has substantial overlap. MIT, on the other hand, does have substantial overlap with other top schools. Unlike the other institutions in the top twenty, Cal Tech appears to draw a more focused group of applicants. In Section III.D, we discussed how such self-selection might bias inference for some speciality schools, with the possibility of some upward bias in the $\boldsymbol{\theta}_{i}$ estimate.

All of the top twenty are private institutions and four-fifths are universities (the exceptions being Amherst, Wellesley, Williams, and Swarthmore). The next twenty institutions 


\begin{tabular}{|c|c|c|}
\hline \multicolumn{3}{|c|}{ Table 3} \\
\hline \multicolumn{3}{|c|}{ A Revealed Preference Ranking of Colleges } \\
\hline rank & College Name & Elopts \\
\hline 1 & Harvard & 2800 \\
\hline 2 & Yale & 2738 \\
\hline 3 & Stanford & 2694 \\
\hline 4 & Cal Tech & 2632 \\
\hline 5 & MIT & 2624 \\
\hline 6 & Princeton & 2608 \\
\hline 7 & Brown & 2433 \\
\hline 8 & Columbia & 2392 \\
\hline 9 & Amherst & 2363 \\
\hline 10 & Dartmouth & 2357 \\
\hline 11 & Wellesley & 2346 \\
\hline 12 & U Penn & 2325 \\
\hline 13 & U Notre Dame & 2279 \\
\hline 14 & Swarthmore & 2270 \\
\hline 15 & Cornell & 2236 \\
\hline 16 & Georgetown & 2218 \\
\hline 17 & Rice & 2214 \\
\hline 18 & Williams & 2213 \\
\hline 19 & Duke & 2209 \\
\hline 20 & U Virginia & 2197 \\
\hline 21 & Northwestern & 2136 \\
\hline 22 & Pomona & 2132 \\
\hline 23 & Berkeley & 2115 \\
\hline 24 & Georgia Tech & 2115 \\
\hline 25 & Middlebury & 2114 \\
\hline 26 & Wesleyan & 2111 \\
\hline 27 & U Chicago & 2104 \\
\hline 28 & Johns Hopkins & 2096 \\
\hline 29 & USC & 2072 \\
\hline 30 & Furman & 2061 \\
\hline 31 & UNC & 2045 \\
\hline 32 & Barnard & 2034 \\
\hline 33 & Oberlin & 2027 \\
\hline 34 & Carleton & 2022 \\
\hline 35 & Vanderbilt & 2016 \\
\hline 36 & UCLA & 2012 \\
\hline 37 & Davidson & 2010 \\
\hline 38 & U Texas & 2008 \\
\hline 39 & NYU & 1992 \\
\hline 40 & Tufts & 1986 \\
\hline 41 & Washington \& Lee & 1983 \\
\hline 42 & U Michigan & 1978 \\
\hline 43 & Vassar & 1978 \\
\hline
\end{tabular}




\begin{tabular}{|c|c|c|}
\hline \multicolumn{3}{|c|}{ Table 3} \\
\hline \multicolumn{3}{|c|}{ A Revealed Preference Ranking of Colleges } \\
\hline rank & College Name & Elopts \\
\hline 44 & Grinnell & 1977 \\
\hline 45 & U Illinois & 1974 \\
\hline 46 & Carnegie Mellon & 1957 \\
\hline 47 & U Maryland & 1956 \\
\hline 48 & William \& Mary & 1954 \\
\hline 49 & Bowdoin & 1953 \\
\hline 50 & Wake Forest & 1940 \\
\hline 51 & Claremont & 1936 \\
\hline 52 & Macalester & 1926 \\
\hline 53 & Colgate & 1925 \\
\hline 54 & Smith & 1921 \\
\hline 55 & U Miami & 1914 \\
\hline 56 & Haverford & 1910 \\
\hline 57 & Mt Holyoke & 1909 \\
\hline 58 & Connecticut College & 1906 \\
\hline 59 & Bates & 1903 \\
\hline 60 & Kenyon & 1903 \\
\hline 61 & Emory & 1888 \\
\hline 62 & Washington $\mathrm{U}$ & 1887 \\
\hline 63 & Occidental & 1883 \\
\hline 64 & Bryn Mawr & 1871 \\
\hline 65 & SMU & 1860 \\
\hline 66 & Lehigh & 1858 \\
\hline 67 & Holy Cross & 1839 \\
\hline 68 & Reed College & 1837 \\
\hline 69 & RPI & 1835 \\
\hline 70 & Florida State & 1834 \\
\hline 71 & Colby & 1820 \\
\hline 72 & UCSB & 1818 \\
\hline 73 & GWU & 1798 \\
\hline 74 & Fordham & 1796 \\
\hline 75 & Sarah Lawrence & 1788 \\
\hline 76 & Bucknell & 1784 \\
\hline 77 & Catholic U & 1784 \\
\hline 78 & U Colorado & 1784 \\
\hline 79 & $\mathrm{U} W$ isconsin & 1780 \\
\hline 80 & Arizona State & 1774 \\
\hline 81 & Wheaton (Il) & 1750 \\
\hline 82 & Rose Hulman & 1745 \\
\hline 83 & UCSC & 1736 \\
\hline 84 & Boston U & 1736 \\
\hline 85 & UCSD & 1732 \\
\hline 86 & Tulane & 1727 \\
\hline
\end{tabular}




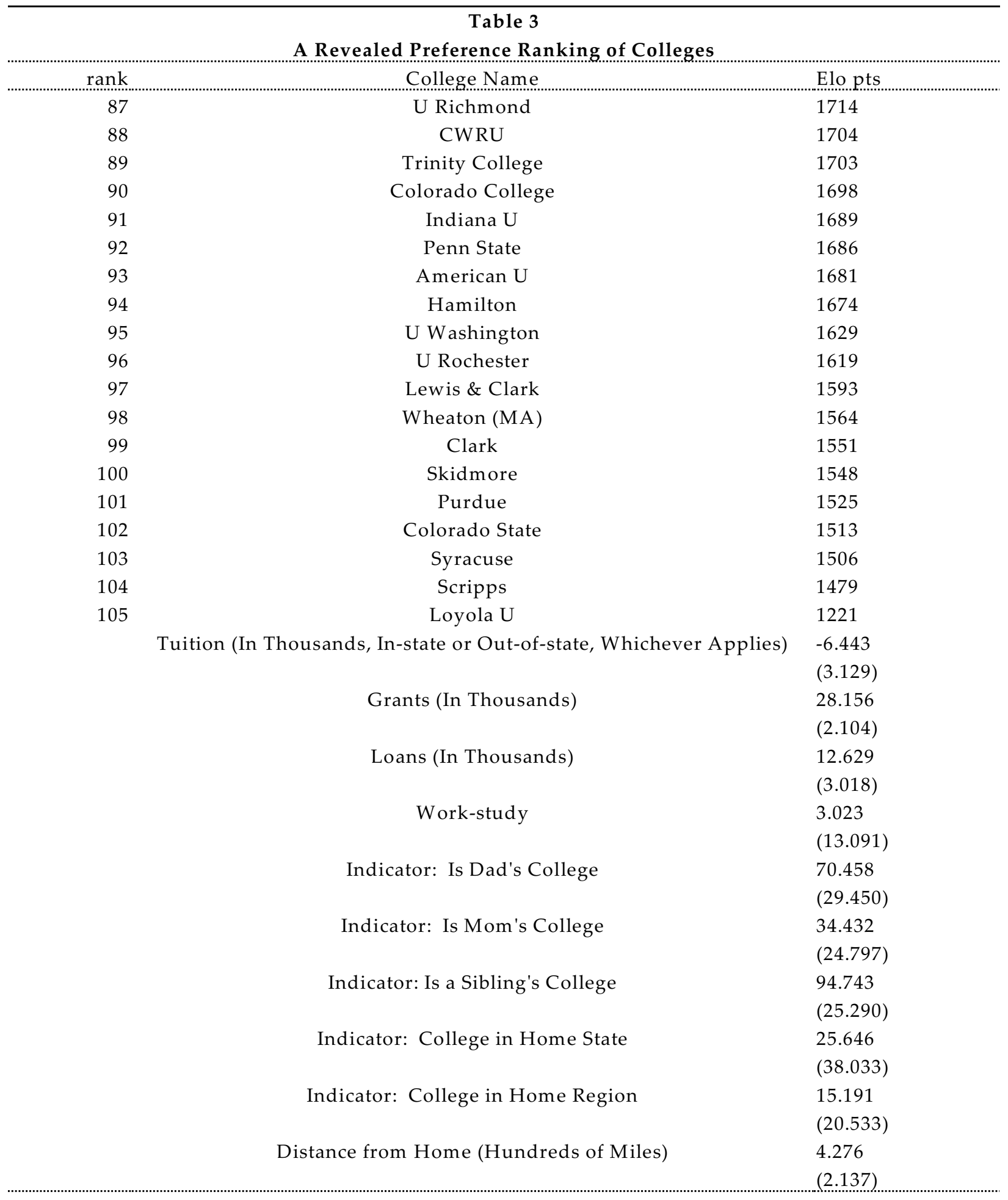

Notes: Estimates based on equation (6) converted into Elo points (see text). Standard errors are in parentheses. 
Table 4: Share of Draws in Which College in the Row is Ranked Higher than the College Various Places Below It

Number of Places Below

\begin{tabular}{|c|c|c|c|c|c|c|c|c|c|c|c|c|c|c|c|c|c|c|c|c|}
\hline College & 1 & 2 & 3 & 4 & 5 & 6 & 7 & 8 & 9 & 10 & 11 & 12 & 13 & 14 & 15 & 16 & 17 & 18 & 19 & 20 \\
\hline Harvard & 96 & 100 & 95 & 100 & 100 & 100 & 100 & 100 & 100 & 100 & 100 & 100 & 100 & 100 & 100 & 100 & 100 & 100 & 100 & 100 \\
\hline Yale & 88 & 78 & 91 & 95 & 100 & 100 & 100 & 100 & 100 & 100 & 100 & 100 & 100 & 100 & 100 & 100 & 100 & 100 & 100 & 100 \\
\hline Stanford & 58 & 62 & 76 & 100 & 100 & 100 & 100 & 100 & 100 & 100 & 100 & 100 & 100 & 100 & 100 & 100 & 100 & 100 & 100 & 100 \\
\hline Cal Tech & 51 & 57 & 89 & 94 & 96 & 96 & 96 & 98 & 98 & 99 & 100 & 100 & 100 & 100 & 100 & 100 & 100 & 100 & 100 & 100 \\
\hline MIT & 63 & 99 & 100 & 100 & 100 & 99 & 100 & 100 & 100 & 100 & 100 & 100 & 100 & 100 & 100 & 100 & 100 & 100 & 100 & 100 \\
\hline Princeton & 96 & 99 & 99 & 99 & 99 & 100 & 100 & 100 & 100 & 100 & 100 & 100 & 100 & 100 & 100 & 100 & 100 & 100 & 100 & 100 \\
\hline Brown & 80 & 87 & 90 & 88 & 97 & 96 & 98 & 100 & 100 & 100 & 100 & 100 & 100 & 100 & 100 & 100 & 100 & 100 & 100 & 100 \\
\hline Columbia & 65 & 66 & 72 & 80 & 85 & 92 & 99 & 99 & 99 & 98 & 100 & 100 & 100 & 100 & 100 & 100 & 100 & 100 & 100 & 100 \\
\hline Amherst & 50 & 59 & 62 & 74 & 85 & 92 & 95 & 97 & 95 & 98 & 97 & 100 & 99 & 100 & 100 & 99 & 98 & 100 & 100 & 100 \\
\hline Dartmouth & 60 & 65 & 76 & 86 & 95 & 97 & 98 & 96 & 99 & 98 & 100 & 100 & 100 & 100 & 100 & 99 & 100 & 100 & 100 & 99 \\
\hline Wellesley & 50 & 64 & 75 & 82 & 85 & 93 & 90 & 92 & 90 & 98 & 98 & 98 & 99 & 97 & 94 & 99 & 99 & 99 & 97 & 100 \\
\hline U Penn & 68 & 81 & 94 & 96 & 97 & 94 & 99 & 98 & 100 & 99 & 100 & 100 & 100 & 98 & 100 & 100 & 100 & 99 & 100 & 100 \\
\hline Notre Dame & 65 & 73 & 78 & 89 & 84 & 88 & 85 & 97 & 96 & 98 & 98 & 95 & 91 & 99 & 99 & 99 & 96 & 100 & 99 & 100 \\
\hline Swarthmore & 53 & 60 & 78 & 73 & 74 & 68 & 90 & 90 & 91 & 93 & 87 & 80 & 95 & 94 & 95 & 91 & 97 & 98 & 98 & 98 \\
\hline Cornell & 61 & 82 & 75 & 81 & 73 & 97 & 95 & 98 & 97 & 94 & 85 & 99 & 99 & 99 & 94 & 100 & 99 & 100 & 99 & 100 \\
\hline Georgetown & 77 & 68 & 71 & 62 & 93 & 91 & 95 & 95 & 89 & 78 & 97 & 97 & 98 & 91 & 99 & 99 & 99 & 99 & 100 & 100 \\
\hline Rice & 45 & 38 & 31 & 62 & 68 & 64 & 75 & 60 & 49 & 75 & 75 & 76 & 77 & 86 & 87 & 89 & 89 & 92 & 93 & 92 \\
\hline Williams & 46 & 39 & 67 & 73 & 69 & 79 & 66 & 56 & 78 & 79 & 79 & 80 & 89 & 89 & 90 & 91 & 94 & 93 & 94 & 94 \\
\hline Duke & 40 & 81 & 82 & 84 & 89 & 77 & 63 & 91 & 91 & 92 & 86 & 97 & 96 & 97 & 96 & 99 & 99 & 98 & 99 & 100 \\
\hline U Virginia & 88 & 87 & 90 & 92 & 83 & 70 & 95 & 94 & 96 & 89 & 98 & 98 & 98 & 98 & 100 & 100 & 99 & 99 & 100 & 100 \\
\hline Northwestern & 62 & 54 & 71 & 49 & 35 & 72 & 72 & 74 & 74 & 88 & 88 & 90 & 90 & 96 & 96 & 93 & 95 & 99 & 98 & 90 \\
\hline Pomona & 40 & 58 & 39 & 28 & 55 & 56 & 55 & 64 & 74 & 75 & 78 & 79 & 83 & 84 & 84 & 85 & 89 & 89 & 83 & 88 \\
\hline Berkeley & 69 & 47 & 33 & 69 & 69 & 72 & 73 & 86 & 88 & 89 & 89 & 95 & 98 & 93 & 95 & 99 & 98 & 90 & 99 & 96 \\
\hline Georgia Tech & 31 & 22 & 45 & 47 & 45 & 59 & 67 & 70 & 71 & 74 & 78 & 78 & 81 & 82 & 85 & 86 & 79 & 84 & 82 & 80 \\
\hline Middlebury & 37 & 67 & 69 & 69 & 72 & 84 & 85 & 88 & 87 & 92 & 92 & 92 & 92 & 96 & 96 & 89 & 96 & 94 & 90 & 97 \\
\hline Wesleyan & 78 & 79 & 80 & 79 & 90 & 90 & 91 & 92 & 95 & 96 & 94 & 95 & 98 & 98 & 92 & 97 & 97 & 93 & 98 & 98 \\
\hline UChicago & 52 & 52 & 63 & 74 & 76 & 79 & 80 & 85 & 86 & 86 & 87 & 93 & 93 & 83 & 92 & 90 & 85 & 95 & 95 & 91 \\
\hline Johns Hopkins & 49 & 62 & 72 & 74 & 77 & 78 & 83 & 84 & 84 & 85 & 91 & 91 & 81 & 91 & 88 & 83 & 93 & 94 & 89 & 95 \\
\hline
\end{tabular}


Table 4: Share of Draws in Which College in the Row is Ranked Higher than the College Various Places Below It

Number of Places Below

\begin{tabular}{|c|c|c|c|c|c|c|c|c|c|c|c|c|c|c|c|c|c|c|c|c|}
\hline College & 1 & 2 & 3 & 4 & 5 & 6 & 7 & 8 & 9 & 10 & 11 & 12 & 13 & 14 & 15 & 16 & 17 & 18 & 19 & 20 \\
\hline USC & 62 & 73 & 76 & 79 & 80 & 86 & 89 & 85 & 87 & 94 & 93 & 82 & 94 & 90 & 84 & 96 & 96 & 91 & 96 & 93 \\
\hline Furman & 54 & 56 & 59 & 61 & 62 & 61 & 68 & 66 & 68 & 70 & 68 & 67 & 70 & 69 & 70 & 76 & 67 & 78 & 74 & 82 \\
\hline UNC & 54 & 58 & 61 & 63 & 61 & 70 & 68 & 73 & 75 & 69 & 71 & 71 & 71 & 76 & 82 & 70 & 84 & 79 & 88 & 72 \\
\hline Barnard & 54 & 58 & 59 & 56 & 66 & 64 & 68 & 70 & 65 & 66 & 68 & 68 & 71 & 78 & 66 & 81 & 75 & 84 & 70 & 84 \\
\hline Oberlin & 54 & 54 & 51 & 64 & 59 & 62 & 66 & 63 & 61 & 63 & 65 & 66 & 74 & 62 & 77 & 72 & 81 & 68 & 82 & 65 \\
\hline Carleton & 49 & 47 & 58 & 55 & 57 & 60 & 59 & 55 & 58 & 62 & 60 & 68 & 55 & 72 & 66 & 75 & 64 & 77 & 59 & 65 \\
\hline Vanderbilt & 47 & 61 & 57 & 61 & 64 & 60 & 59 & 61 & 63 & 65 & 74 & 60 & 79 & 70 & 82 & 65 & 81 & 64 & 68 & 81 \\
\hline UCLA & 64 & 61 & 65 & 68 & 62 & 62 & 64 & 66 & 70 & 77 & 63 & 81 & 74 & 85 & 68 & 85 & 67 & 70 & 83 & 87 \\
\hline Davidson & 46 & 45 & 49 & 50 & 44 & 48 & 53 & 49 & 58 & 46 & 64 & 57 & 66 & 57 & 69 & 50 & 56 & 67 & 74 & 60 \\
\hline U Texas & 50 & 55 & 55 & 49 & 53 & 58 & 55 & 65 & 51 & 70 & 63 & 74 & 61 & 75 & 55 & 61 & 74 & 79 & 65 & 66 \\
\hline NYU & 56 & 56 & 48 & 54 & 58 & 56 & 68 & 50 & 73 & 65 & 77 & 61 & 79 & 56 & 62 & 76 & 82 & 66 & 69 & 66 \\
\hline Tufts & 51 & 42 & 48 & 54 & 49 & 61 & 44 & 68 & 60 & 71 & 58 & 73 & 50 & 57 & 71 & 78 & 62 & 63 & 61 & 83 \\
\hline Wash \& Lee & 44 & 47 & 52 & 48 & 56 & 45 & 62 & 56 & 64 & 55 & 67 & 48 & 54 & 65 & 71 & 60 & 58 & 57 & 75 & 80 \\
\hline U Michigan & 54 & 59 & 58 & 70 & 52 & 74 & 66 & 79 & 62 & 79 & 58 & 63 & 77 & 83 & 68 & 70 & 67 & 87 & 96 & 98 \\
\hline Vassar & 56 & 51 & 62 & 47 & 68 & 61 & 71 & 58 & 73 & 51 & 58 & 71 & 78 & 63 & 64 & 62 & 82 & 89 & 90 & 79 \\
\hline Grinnell & 44 & 53 & 42 & 59 & 53 & 61 & 53 & 64 & 46 & 53 & 62 & 69 & 57 & 55 & 55 & 72 & 77 & 76 & 68 & 68 \\
\hline U Illinois & 64 & 45 & 70 & 61 & 74 & 58 & 75 & 51 & 59 & 74 & 80 & 64 & 65 & 62 & 85 & 94 & 96 & 81 & 76 & 70 \\
\hline Carnegie Mell & 34 & 57 & 50 & 61 & 51 & 65 & 40 & 49 & 64 & 71 & 55 & 53 & 52 & 75 & 85 & 85 & 71 & 69 & 63 & 76 \\
\hline U Maryland & 72 & 64 & 75 & 61 & 76 & 55 & 62 & 74 & 80 & 65 & 67 & 64 & 85 & 93 & 95 & 82 & 78 & 72 & 86 & 79 \\
\hline William Mary & 44 & 53 & 46 & 58 & 33 & 43 & 56 & 64 & 49 & 46 & 45 & 69 & 76 & 76 & 64 & 63 & 57 & 69 & 63 & 72 \\
\hline Bowdoin & 59 & 51 & 62 & 41 & 49 & 62 & 68 & 54 & 52 & 51 & 73 & 80 & 80 & 69 & 68 & 62 & 74 & 68 & 76 & 79 \\
\hline Wake Forest & 44 & 55 & 29 & 40 & 54 & 62 & 46 & 42 & 42 & 67 & 74 & 74 & 62 & 62 & 55 & 68 & 62 & 71 & 75 & 84 \\
\hline Claremont & 59 & 43 & 49 & 58 & 64 & 52 & 51 & 50 & 68 & 72 & 71 & 63 & 64 & 59 & 68 & 63 & 71 & 74 & 80 & 74 \\
\hline Macalester & 28 & 37 & 50 & 57 & 43 & 38 & 38 & 61 & 67 & 65 & 56 & 58 & 51 & 61 & 56 & 67 & 68 & 78 & 69 & 77 \\
\hline Colgate & 58 & 71 & 77 & 62 & 63 & 61 & 82 & 89 & 90 & 78 & 75 & 69 & 83 & 76 & 82 & 87 & 93 & 89 & 95 & 96 \\
\hline Smith & 62 & 69 & 55 & 54 & 52 & 73 & 78 & 77 & 68 & 69 & 62 & 73 & 68 & 75 & 78 & 85 & 80 & 85 & 88 & 60 \\
\hline U Miami & 58 & 44 & 40 & 40 & 61 & 67 & 65 & 57 & 59 & 52 & 62 & 57 & 66 & 68 & 78 & 69 & 76 & 81 & 49 & 63 \\
\hline Haverford & 37 & 32 & 32 & 53 & 57 & 56 & 49 & 52 & 45 & 54 & 49 & 59 & 61 & 71 & 62 & 69 & 72 & 42 & 56 & 66 \\
\hline
\end{tabular}


Table 4: Share of Draws in Which College in the Row is Ranked Higher than the College Various Places Below It

Number of Places Below

\begin{tabular}{|c|c|c|c|c|c|c|c|c|c|c|c|c|c|c|c|c|c|c|c|c|}
\hline College & 1 & 2 & 3 & 4 & 5 & 6 & 7 & 8 & 9 & 10 & 11 & 12 & 13 & 14 & 15 & 16 & 17 & 18 & 19 & 20 \\
\hline Mt Holyoke & 48 & 47 & 67 & 72 & 70 & 62 & 64 & 57 & 67 & 62 & 70 & 72 & 80 & 74 & 80 & 83 & 55 & 67 & 77 & 68 \\
\hline Connecticut C. & 48 & 72 & 80 & 79 & 68 & 66 & 60 & 73 & 67 & 74 & 80 & 86 & 81 & 87 & 90 & 58 & 71 & 85 & 71 & 83 \\
\hline Bates & 72 & 79 & 79 & 68 & 66 & 61 & 72 & 67 & 74 & 78 & 86 & 80 & 86 & 88 & 58 & 70 & 83 & 71 & 82 & 90 \\
\hline Kenyon & 53 & 51 & 44 & 48 & 42 & 49 & 46 & 56 & 56 & 68 & 58 & 64 & 70 & 39 & 53 & 64 & 56 & 61 & 73 & 76 \\
\hline Emory & 46 & 40 & 45 & 38 & 46 & 41 & 55 & 54 & 68 & 56 & 65 & 72 & 34 & 50 & 62 & 55 & 61 & 76 & 76 & 62 \\
\hline Wash. U & 43 & 47 & 41 & 49 & 44 & 57 & 59 & 73 & 59 & 70 & 77 & 36 & 53 & 67 & 57 & 65 & 81 & 80 & 65 & 75 \\
\hline Occidental & 53 & 46 & 55 & 50 & 61 & 62 & 73 & 64 & 72 & 76 & 42 & 57 & 69 & 60 & 67 & 79 & 80 & 68 & 76 & 81 \\
\hline Bryn Mawr & 44 & 52 & 48 & 56 & 57 & 66 & 58 & 63 & 67 & 41 & 53 & 63 & 57 & 60 & 70 & 72 & 62 & 70 & 71 & 78 \\
\hline SMU & 58 & 54 & 63 & 63 & 72 & 64 & 70 & 74 & 47 & 60 & 69 & 62 & 67 & 76 & 78 & 69 & 76 & 78 & 85 & 88 \\
\hline Lehigh & 46 & 57 & 58 & 68 & 58 & 65 & 71 & 38 & 53 & 65 & 57 & 62 & 75 & 77 & 64 & 73 & 77 & 87 & 90 & 89 \\
\hline Holy Cross & 60 & 60 & 70 & 62 & 67 & 72 & 42 & 56 & 67 & 59 & 65 & 76 & 77 & 66 & 74 & 77 & 85 & 89 & 88 & 87 \\
\hline Reed College & 49 & 58 & 49 & 54 & 59 & 33 & 46 & 54 & 51 & 51 & 61 & 66 & 55 & 64 & 64 & 71 & 77 & 77 & 77 & 78 \\
\hline RPI & 62 & 50 & 57 & 63 & 32 & 47 & 57 & 52 & 54 & 68 & 71 & 58 & 69 & 71 & 81 & 87 & 85 & 83 & 85 & 85 \\
\hline Florida State & 38 & 43 & 49 & 24 & 37 & 45 & 43 & 41 & 53 & 60 & 47 & 59 & 58 & 67 & 74 & 74 & 74 & 76 & 75 & 68 \\
\hline Colby & 57 & 64 & 31 & 47 & 57 & 51 & 54 & 68 & 71 & 57 & 68 & 70 & 81 & 87 & 86 & 84 & 86 & 86 & 79 & 88 \\
\hline UCSB & 59 & 25 & 42 & 52 & 48 & 47 & 63 & 68 & 53 & 65 & 68 & 81 & 88 & 85 & 83 & 85 & 85 & 77 & 88 & 82 \\
\hline GWU & 22 & 37 & 44 & 43 & 41 & 56 & 62 & 48 & 61 & 60 & 73 & 81 & 80 & 77 & 80 & 80 & 70 & 82 & 75 & 76 \\
\hline Fordham & 63 & 73 & 64 & 72 & 81 & 82 & 71 & 78 & 82 & 89 & 92 & 91 & 90 & 91 & 91 & 87 & 93 & 90 & 89 & 89 \\
\hline Sarah Lawr. & 59 & 53 & 56 & 66 & 70 & 60 & 68 & 69 & 76 & 81 & 81 & 81 & 82 & 81 & 76 & 83 & 79 & 79 & 80 & 91 \\
\hline Bucknell & 47 & 46 & 60 & 65 & 51 & 63 & 63 & 74 & 80 & 80 & 78 & 81 & 81 & 73 & 82 & 76 & 78 & 78 & 92 & 94 \\
\hline Catholic U & 51 & 60 & 64 & 54 & 63 & 62 & 67 & 73 & 74 & 73 & 74 & 73 & 69 & 75 & 70 & 72 & 73 & 84 & 87 & 78 \\
\hline U Colorado & 64 & 69 & 54 & 66 & 68 & 80 & 86 & 84 & 83 & 84 & 84 & 77 & 86 & 81 & 81 & 81 & 94 & 97 & 87 & 57 \\
\hline $\mathrm{U}$ Wisconsin & 58 & 44 & 57 & 54 & 67 & 75 & 75 & 73 & 76 & 76 & 67 & 79 & 70 & 72 & 72 & 90 & 93 & 80 & 48 & 82 \\
\hline Arizona St & 39 & 51 & 45 & 53 & 63 & 63 & 64 & 65 & 64 & 57 & 66 & 58 & 61 & 63 & 80 & 85 & 71 & 43 & 74 & 83 \\
\hline Wheaton (IL) & 60 & 59 & 67 & 73 & 74 & 73 & 75 & 74 & 69 & 76 & 69 & 72 & 73 & 86 & 89 & 79 & 53 & 82 & 88 & 87 \\
\hline Rose Hulman & 46 & 52 & 59 & 60 & 61 & 62 & 61 & 56 & 62 & 55 & 58 & 60 & 75 & 79 & 68 & 42 & 72 & 78 & 77 & 48 \\
\hline UCSC & 61 & 71 & 69 & 70 & 71 & 71 & 63 & 73 & 65 & 67 & 69 & 87 & 91 & 77 & 45 & 80 & 89 & 86 & 53 & 94 \\
\hline Boston U & 64 & 63 & 63 & 66 & 65 & 56 & 68 & 55 & 61 & 62 & 85 & 91 & 73 & 40 & 77 & 87 & 84 & 45 & 95 & 81 \\
\hline
\end{tabular}


Table 4: Share of Draws in Which College in the Row is Ranked Higher than the College Various Places Below It

Number of Places Below

\begin{tabular}{|c|c|c|c|c|c|c|c|c|c|c|c|c|c|c|c|c|c|c|c|c|}
\hline College & 1 & 2 & 3 & 4 & 5 & 6 & 7 & 8 & 9 & 10 & 11 & 12 & 13 & 14 & 15 & 16 & 17 & 18 & 19 & 20 \\
\hline Ucsd & 51 & 53 & 55 & 53 & 46 & 55 & 43 & 49 & 52 & 77 & 83 & 65 & 34 & 69 & 79 & 78 & 37 & 89 & 74 & 89 \\
\hline Tulane & 52 & 53 & 52 & 45 & 54 & 42 & 48 & 52 & 73 & 80 & 63 & 33 & 68 & 77 & 76 & 37 & 87 & 73 & 87 & 61 \\
\hline U Richmond & 50 & 49 & 44 & 51 & 41 & 46 & 49 & 68 & 74 & 59 & 33 & 65 & 73 & 73 & 36 & 82 & 69 & 83 & 60 & \\
\hline CWRU & 47 & 43 & 50 & 39 & 45 & 49 & 68 & 75 & 60 & 32 & 65 & 74 & 72 & 35 & 84 & 70 & 85 & 59 & & \\
\hline Trinity Coll & 44 & 52 & 40 & 46 & 51 & 72 & 78 & 62 & 33 & 66 & 76 & 74 & 36 & 85 & 71 & 86 & 61 & & & \\
\hline Colorado Coll & 58 & 48 & 53 & 56 & 75 & 80 & 67 & 37 & 69 & 78 & 77 & 41 & 86 & 74 & 87 & 64 & & & & \\
\hline Indiana U & 38 & 45 & 48 & 71 & 77 & 60 & 32 & 66 & 75 & 74 & 34 & 85 & 70 & 86 & 60 & & & & & \\
\hline Penn State & 56 & 59 & 81 & 87 & 69 & 37 & 73 & 83 & 81 & 42 & 92 & 77 & 91 & 66 & & & & & & \\
\hline American $U$ & 54 & 75 & 80 & 65 & 34 & 69 & 78 & 76 & 39 & 88 & 74 & 87 & 63 & & & & & & & \\
\hline Hamilton & 69 & 75 & 61 & 33 & 65 & 73 & 72 & 36 & 82 & 69 & 84 & 60 & & & & & & & & \\
\hline U Washington & 57 & 44 & 21 & 51 & 57 & 59 & 21 & 70 & 55 & 74 & 47 & & & & & & & & & \\
\hline U Rochester & 38 & 17 & 46 & 51 & 52 & 17 & 64 & 50 & 70 & 43 & & & & & & & & & & \\
\hline Lewis\&Clark & 26 & 55 & 61 & 61 & 28 & 72 & 59 & 75 & 51 & & & & & & & & & & & \\
\hline Wheaton (Ma) & 77 & 82 & 82 & 56 & 87 & 79 & 88 & 72 & & & & & & & & & & & & \\
\hline Clark & 55 & 56 & 25 & 64 & 53 & 68 & 47 & & & & & & & & & & & & & \\
\hline Skidmore & 52 & 18 & 62 & 49 & 67 & 43 & & & & & & & & & & & & & & \\
\hline Purdue & 19 & 60 & 48 & 64 & 41 & & & & & & & & & & & & & & & \\
\hline Colorado St & 88 & 78 & 90 & 69 & & & & & & & & & & & & & & & & \\
\hline Syracuse & 39 & 58 & 35 & & & & & & & & & & & & & & & & & \\
\hline Scripps & 66 & 44 & & & & & & & & & & & & & & & & & & \\
\hline Loyola U & 31 & & & & & & & & & & & & & & & & & & & \\
\hline
\end{tabular}


are, however, a mix of public and private, small and large, colleges and universities. They are also more geographically diverse. They include private schools from middle and southern states: University of Chicago, Furman, Carleton, Davidson, Northwestern, Oberlin, Vanderbilt. There are also several public universities: UC - Berkeley, UCLA, Georgia Tech, U Texas, North Carolina.

The colleges ranked from 41 to 106 include a good number of states' "flagship" universities, numerous liberal arts colleges, several private universities, and a few more institutes of technology. ${ }^{17}$ As a rule, the lower one goes in the revealed preference ranking, the less distinct is a college's desirability from that of its immediate neighbors in the ranking. Among the top ten colleges, we generally enjoy confidence of about 75 percent that a college is ranked higher than the college listed one below it. To achieve the same level of confidence for colleges ranked eleven to twenty, we need to compare a college with one that is about four places below it. To achieve 75 percent confidence with the colleges ranked twenty to 30 , we need to compare a college with one that is about six places below it. In short, our confidence about the exact rank order falls with colleges' measured desirability. There are two reasons why our confidence falls. First, there may be less consensus among students about colleges' desirability as we move from the best known colleges to those with less wide reputations. Second, owing to the nature of our sample, our data are thickest for the most selective colleges. We did a simple test to determine whether data thickness was primarily responsible for the fall off in confidence: we randomly selected only 20 observations per college. With these data, we found that about two-thirds of the drop-off in confidence disappeared. That is, if our data were equally representative for all colleges, our confidence about the exact rank order would probably fall only about one third as fast as it does.

17 The students in our sample who had a Florida resident as a parent were the first cohort to receive Florida A-Plus Scholarships, which allowed them to attend public universities in Florida for free. The initiation of the scholarships generated considerable excitement and may have raised the ranking of public universities in Florida, such as Florida State, among students in our sample. 
B. Comparing Measures of Revealed Preference

For the colleges that are in the top twenty based on revealed preference, Table 5 shows what their rankings would be if they were based on, respectively, the admissions and matriculation rates. We use crude admissions and matriculation rates from the College Board's Standard Research Complication, the same data as form the "Common Data Set" published on colleges' websites and used by college guides like U.S. News.

\begin{tabular}{|c|c|c|c|}
\hline \multicolumn{4}{|c|}{$\begin{array}{c}\text { Table } 5 \\
\text { A Comparison of the Revealed Preference Ranking of Colle } \\
\text { and Rankings Based on the Crude Admissions and Matriculatio }\end{array}$} \\
\hline & \multicolumn{3}{|c|}{ National Rank Based On: } \\
\hline & $\begin{array}{r}\text { Revealed Preference (based on } \\
\text { Matriculation Tournaments) }\end{array}$ & \multicolumn{2}{|c|}{ Admissions Rate Matriculation Rate } \\
\hline Harvard & 1 & 4 & 139 \\
\hline Yale & 2 & 12 & 309 \\
\hline Stanford & 3 & 7 & 297 \\
\hline Cal Tech & 4 & 9 & 854 \\
\hline MIT & 5 & 13 & 422 \\
\hline Princeton & 6 & 5 & 266 \\
\hline Brown & 7 & 14 & 561 \\
\hline Columbia & 8 & 6 & 438 \\
\hline Amherst & 9 & 19 & 916 \\
\hline Dartmouth & 10 & 20 & 647 \\
\hline Wellesley & 11 & 23 & 492 \\
\hline U Penn & 12 & 104 & 794 \\
\hline U Notre Dame & 13 & 58 & 459 \\
\hline Swarthmore & 14 & 28 & 1016 \\
\hline Cornell & 15 & 45 & 649 \\
\hline Georgetown & 16 & 22 & 703 \\
\hline Rice & 17 & 25 & 996 \\
\hline Williams & 18 & 29 & 797 \\
\hline Duke & 19 & 32 & 859 \\
\hline U Virginia & 20 & 76 & 630 \\
\hline
\end{tabular}

Looking at Table 5, we observe that most of the top twenty colleges based on revealed preference are not in the top twenty based on the admissions and matriculation rates. Indeed, 
the admissions rate puts 10 of them outside the top twenty and the matriculation rate puts all of them outside the top 100. Clearly, there are many colleges with low admissions rates or high matriculation rates that are not perceived to be highly desirable. Apart from convenience, we are unable to frame an argument for why the crude rates have any advantage over the procedures for revealing preference that we outline in this paper.

\section{Regional Rankings}

Table 6 shows the rankings we obtain if we estimate the matriculation model separately for students from each of the nine census divisions of the U.S. The nine divisions are: Division 1: Connecticut, Massachusetts, Maine, New Hampshire, Rhode Island, Vermont; Division 2: New Jersey, New York, Pennsylvania;

Division 3: Illinois, Indiana, Michigan, Ohio, Wisconsin;

Division 4: Kansas, Minnesota, Missouri, Nebraska;

Division 5: D.C., Florida, Georgia, Maryland, North Carolina, South Carolina, Virginia;

Division 6: Alabama, Kentucky, Tennessee;

Division 7: Arkansas, Louisiana, Oklahoma, Texas;

Division 8: Arizona, Colorado, Idaho, Montana, New Mexico, Nevada, Utah, Wyoming; Division 9: California, Hawaii, Oregon, Washington.

We make no great claims for these regional rankings because the sample for each region is small. Rather, we show Table 6 so that the reader can see how the regional rankings combine to form a truly national ranking at the top. Because the regional samples are small, some schools do not get ranked in some regions, and thus we have left spaces where Elo points suggest that a school ranked in other regions is missing. For instance, in division 6 (Alabama, Tennessee, Kentucky), neither Cal Tech nor Stanford is ranked. Because the regional samples are small, we merely group schools outside of the top 30 (see note below the table).

Looking at Table 6, the most noteworthy thing is the great consistency of the ranking of the top ten institutions. Each region reproduces the national ranking, with a couple of exceptions. In region 7 and 9, Stanford is ranked above MIT, whereas MIT is usually ranked higher. Also, Amherst and Dartmouth often trade places in the rankings. Among the 


\begin{tabular}{|c|c|c|c|c|c|c|c|c|}
\hline \multicolumn{9}{|c|}{ Table 6: An Example of Regional Preference Rankings of Colleges } \\
\hline \multicolumn{9}{|c|}{ Ranking among Students From: } \\
\hline Region 1: & Region 2: & Region 3: & Region 4: & Region 5: & Region 6: & Region 7: & Region 8: & Region 9: \\
\hline $\begin{array}{l}\mathrm{CT}, \mathrm{MA}, \mathrm{ME}, \\
\mathrm{NH}, \mathrm{RI}, \mathrm{VT}\end{array}$ & NJ, NY, PA & $\begin{array}{l}\mathrm{IL}, \mathrm{IN}, \mathrm{MI}, \mathrm{OH}, \\
\mathrm{WI}\end{array}$ & $\begin{array}{l}\mathrm{KS}, \mathrm{MN}, \mathrm{MO}, \\
\mathrm{NE}\end{array}$ & $\begin{array}{l}\mathrm{DC}, \mathrm{FL}, \mathrm{GA}, \\
\mathrm{MD}, \mathrm{NC}, \mathrm{SC}, \mathrm{VA}\end{array}$ & $\mathrm{AL}, \mathrm{KY}, \mathrm{TN}$ & AR, LA, OK, TX & $\begin{array}{l}\text { AZ, CO, ID, MT, } \\
\text { NM, NV, UT, WY }\end{array}$ & $\begin{array}{l}\text { CA, HI, OR, } \\
\text { WA }\end{array}$ \\
\hline 1 Harvard & Harvard & Harvard & Harvard & Harvard & Harvard & Harvard & Harvard & Harvard \\
\hline 2 Cal Tech & Cal Tech & Cal Tech & Cal Tech & Cal Tech & & Cal Tech & Cal Tech & Cal Tech \\
\hline 3 Yale & Yale & Yale & Yale & Yale & Yale & Yale & Yale & Yale \\
\hline 4 MIT & MIT & MIT & MIT & MIT & MIT & Stanford & Stanford & Stanford \\
\hline 5 Stanford & Princeton & Stanford & Princeton & Stanford & & MIT & Princeton & MIT \\
\hline 6 Princeton & Stanford & Princeton & Stanford & Princeton & Princeton & Princeton & Brigham Young & Princeton \\
\hline 7 Brown & Brown & Brown & Brown & Brown & Brown & Brown & Brown & Brown \\
\hline 8 Columbia & Columbia & Columbia & Amherst & Columbia & Columbia & Columbia & Columbia & Columbia \\
\hline 9 Dartmouth & Dartmouth & Amherst & Dartmouth & Dartmouth & Dartmouth & Dartmouth & Dartmouth & Dartmouth \\
\hline 10 Amherst & Amherst & Dartmouth & Notre Dame & Amherst & Wellesley & Amherst & U Penn & Amherst \\
\hline 11 Wellesley & Wellesley & Wellesley & U Penn & Notre Dame & U Penn & Wellesley & Amherst & U Penn \\
\hline 12 Notre Dame & Notre Dame & U Penn & Swarthmore & Wellesley & Amherst & U Penn & Notre Dame & Wellesley \\
\hline 13 U Penn & U Penn & Notre Dame & Williams & U Penn & Duke & Notre Dame & Williams & Notre Dame \\
\hline 14 Swarthmore & Cooper Union & Swarthmore & Cornell & Swarthmore & Swarthmore & Cornell & Swarthmore & Cornell \\
\hline 15 Rice & Swarthmore & Cornell & Duke & Cornell & Cornell & Rice & Cornell & Swarthmore \\
\hline 16 Cornell & Cornell & Duke & Georgetown & Duke & Georgia Tech & Duke & Duke & Georgetown \\
\hline 17 Georgetown & Georgetown & Rice & U Virginia & Georgetown & Williams & Williams & Rice & Duke \\
\hline 18 Duke & Rice & Williams & Rice & Rice & Georgetown & Georgetown & U Virginia & Rice \\
\hline 19 Williams & Duke & Georgetown & Wesleyan & Williams & Rice & U Virginia & Georgetown & Cooper Union \\
\hline 20 U Virginia & Williams & U Virginia & USC & Harvey Mudd & U Virginia & Wesleyan & Wesleyan & Williams \\
\hline 21 Wesleyan & U Virginia & Wesleyan & Northwestern & U Virginia & Wesleyan & Northwestern & Pomona & U Virginia \\
\hline 22 Harvey Mudd & Harvey Mudd & Harvey Mudd & U Chicago & Wesleyan & Claremont & Berkeley & Middlebury & Harvey Mudd \\
\hline 23 Northwestern & Wesleyan & Northwestern & Pomona & Northwestern & Northwestern & Georgia Tech & Berkeley & Wesleyan \\
\hline 24 Pomona & Northwestern & Pomona & Georgia Tech & Pomona & Fordham & USC & Northwestern & Pomona \\
\hline 25 U Chicago & Pomona & Middlebury & Johns Hopkins & Georgia Tech & Berkeley & U Chicago & USC & Berkeley \\
\hline 26 Middlebury & U Chicago & Johns Hopkins & U Texas & Berkeley & USC & Johns Hopkins & U Chicago & Northwestern \\
\hline 27 Johns Hopkins & Middlebury & Berkeley & UNC & Middlebury & Pomona & Pomona & Georgia Tech & Johns Hopkins \\
\hline 28 USC & Berkeley & USC & Vanderbilt & U Chicago & U Chicago & Middlebury & $\mathrm{UNC}$ & USC \\
\hline 29 Berkeley & Johns Hopkins & U Chicago & Carleton & Johns Hopkins & UNC & U Texas & Johns Hopkins & U Chicago \\
\hline 30 Georgia Tech & Georgia Tech & U Texas & Oberlin & USC & Vanderbilt & UNC & Oberlin & Middlebury \\
\hline
\end{tabular}




\section{Notes for Table 6}

Next 30 colleges, for each region:

Region 1 (CT, MA, ME, NH, RI, VT): UNC, Oberlin, Vanderbilt, U Florida, Barnard, Carleton, Furman, George Mason, Davidson, U Michigan, UCLA, NYU,

Tufts, Claremont Mckenna, U Illinois, Vassar, Washington and Lee, Grinnell, Pitzer, Carnegie Mellon, U Maryland, Wake Forest, Kenyon, Bowdoin, William and Mary, Colgate, SMU, Macalester, U Miami.

Region 2 (NJ, NY,PA): USC, U Texas, UNC, Carleton, Barnard, Vanderbilt, Oberlin, Davidson, Washington and Lee, UCLA, NYU, Tufts, U Michigan, U Florida, Furman, Vassar, Grinnell, U Illinois, St. John's, Bowdoin, U Maryland, Kenyon, William and Mary, Carnegie Mellon, Wake Forest, Claremont Mckenna, Smith, Colgate, Pitzer, Macalester.

Region 3 (IL, IN, MI, OH, WI): UNC, Claremont Mckenna, Fordham, Carleton, USC, Vanderbilt, Oberlin, Davidson, Barnard, UCLA, U Illinois, SMU,

Washington and Lee, Bradley, U Florida, U Michigan, Tufts, Vassar, NYU, Grinnell, U Missouri, Wake Forest, Bowdoin, Carnegie Mellon, Illinois Wesleyan, U Oregon, Haverford, Macalester, Smith, William and Mary.

Region 4 (KS, MN, MO, NE): Washington and Lee, Vassar, Davidson, Tufts, Furman, Bowdoin, Colgate, Grinnell, U Michigan, New York, Rhodes, U Illinois, SMU, Haverford, Macalester, Kenyon, Wake Forest, U Missouri, Connecticut College, U Maryland, Carnegie Mellon, Bradley, Sarah Lawrence, Lehigh,

Washington U., Bates, Bucknell, College of William and Mary, U Miami, Colby.

Region 5 (DC, FL, GA, MD, NC, SC, VA): UNC, U Texas, U Florida, Fordham, Barnard, Vanderbilt, Carleton, UCLA, Davidson, Oberlin, U Michigan, Tufts, Vassar, U Maryland, Furman, U Illinois, Washington and Lee, NYU, Grinnell, U. of the South, Bowdoin, Kenyon, Carnegie Mellon, William and Mary, Wake Forest, Macalester, Smith, U Miami, Colgate, Haverford.

Region 6 (AL, KY, TN): Furman, Johns Hopkins, Middlebury, UCLA, U Texas, Barnard, Davidson, U the South, Wake Forest, SMU, Carleton, Oberlin, U Michigan, U Illinois, Texas A\&M, NYU, Rhodes, Vassar, Occidental, Smith, Clemson, Kenyon, Carnegie Mellon, Bowdoin, William and Mary, Bates, U Miami, Washington and Lee, Washington U., Haverford.

Region 7 (AR, LA, OK, TX): Furman, Oberlin, Carleton, UCLA, Rhodes, Vanderbilt, Barnard, Davidson, Fordham, U Michigan, Washington and Lee, Tufts, NYU, Wake Forest, U Illinois, Bowdoin, Vassar, Carnegie Mellon, Colgate, Smith, U Maryland, SMU, Macalester, Haverford, Washington U., Connecticut College, Emory, Mount Holyoke, Bucknell, Bryn Mawr.

Region 8 (AZ, CO, ID, MT, NM, NV, UT, WY): Barnard, Claremont Mckenna, Carleton, Vanderbilt, UCLA, NYU, Wake Forest, Tufts, Macalester, Washington and Lee, U Michigan, Bowdoin, U Oregon, Vassar, Colgate, U Miami, Mount Holyoke, Carnegie Mellon, Grinnell, Haverford, William and Mary, Emory, U Missouri, Whitman, U Colorado, Washington U., Santa Clara, U. Arizona, UCSB, Occidental.

Region 9 (CA, HI, OR, WA): U Texas, SMU, UNC, UCLA, Carleton, Barnard, Oberlin, Davidson, Vanderbilt, NYU, Washington and Lee, Tufts, U Illinois, U Michigan, U Oregon, Pitzer, Vassar, Bowdoin, Carnegie Mellon, Grinnell, Smith, Wake Forest, Macalester, Fordham, St. John's, Claremont Mckenna, William and Mary, Haverford, Emory, Whitman. 
institutions ranked 11 to 30 , there is considerable consistency overall, and nearly all of the changes in rank order appear to be noise, probably due to the small regional samples. The overall impression is one of consistency: the national ranking is truly national, at least at the top.

Regionalism is more evident in the colleges ranked 31 to 60 , which are shown in the notes below Table 6 . While much of the variation in the ranking is noise at this point, owing to the small regional samples, it is notable that Southern colleges do better in the South (U. of the South, Clemson, and Rhodes are the most obvious), Midwestern colleges do better in the Midwest (Bradley is the most obvious), and Western colleges do better in the West (Whitman, Santa Clara, Occidental, and Pitzer are the most obvious). In addition, flagship state universities are likely to show up in their region, even if not in distant regions (U Oregon, $\mathrm{U}$ Colorado, and U Arizona are the most obvious). However, for the colleges ranked 31 to 60 , the overwhelming impression is that the regional rankings are not very regional. The regional favorites never represent more than ten percent of the 30, and most of the colleges that appear show up in every region.

Perhaps the single most interesting college in Table 6 is Brigham Young, which appears in the top 10, between Princeton and Brown, in region 8 (which contains Utah). We have checked and determined that, if we were to compute a Utah-specific ranking, Brigham Young would rank even higher. The dramatic appearance of Brigham Young in the top 10 almost certainly occurs because the college is particularly desirable in the eyes of Mormon students. ${ }^{18}$ We cannot verify this conjecture because we did not ask students about their religion, but this leads us back to our general point about latent desirability and self-selection into applicant pools. The reason that Brigham Young wins so many tournaments with Utah students is that it is truly more desirable to them. Similarly, the reason that a bit of regionalism appears is that University of the South, say, is truly more desirable to Southerners. This is not a problem we

18 The reason that Brigham Young does not appear in the national ranking is that, in our sample, it competes in fewer than six regions. 
need to "fix" in the national ranking. It is simply an indicator that, with sufficient data, it would be reasonable to compute sub-rankings for identifiable groups of students with welldefined tastes. We know now that these rankings will tend to join up at the top. A benefit of computing sub-rankings is that some colleges' performance in the national rankings depends on the fact that they are especially popular with a well-defined set of students who self-select into applying (think of Cal Tech). Self-selection does not appear to be an important concern with our national ranking, except perhaps for the engineering schools. However, we speculate that it would be appropriate to construct sub-rankings once we got much outside of this group.

\section{Conclusions}

In this paper, we show how students' college choice behavior can be used to generate revealed preference rankings of American colleges and universities. Using a data set on the college application and matriculation choices of highly meritorious American students, we construct examples of a national revealed preference ranking and regional revealed preference rankings. Our procedure generates a revealed preference ranking which would be very difficult for a college to manipulate with strategic admissions behavior.

Given the strong demand for measures of revealed preference among parents and students, it is clear that colleges will be forced to provide some such information and college guides like U.S. News will be forced to give substantial weight to such information. In the absence of a revealed preference ranking method such as ours, colleges and college guides use two flawed, manipulable proxies: the crude admissions rate and crude matriculation rate. These proxies are not only misleading; they induce colleges to engage in distorted conduct that decreases the colleges' real selectivity while increasing the colleges' apparent desirability, as measured by the proxies. So long as colleges are judged based on the crude admissions and matriculation rates, it is unlikely that all colleges will eliminate strategic admissions or roll back early decision programs, which are key means for manipulating the proxies. Many college administrators correctly perceive that they are in a bad equilibrium. Yet, so long as colleges' find it advantageous to use early decision and other costly admissions strategies, the bad 
equilibrium is likely to persist.

Gathering our data was a moderately costly undertaking for researchers, but the cost would be a trivial share of the revenues associated with college guides. Moreover, at least some of the data are already compiled by organizations like The College Board and the ACT, so that gathering a highly representative sample should be very feasible. If a revealed preference ranking constructed using our procedure were used in place of manipulable indicators like the crude admissions rate and crude matriculation rate, much of the pressure on colleges to manipulate admissions would be relieved. In addition, students and parents would be informed by significantly more accurate measures of revealed preference. We close by reminding readers that measures of revealed preference are just that: measures of desirability based on students and families making college choices. They do not necessarily correspond to educational quality. 


\section{References}

Avery, Christopher, Andrew Fairbanks, and Richard Zeckhauser. The Early Admissions Game: Joining the Elite. Cambridge, MA: Harvard University Press, 2003.

Avery, Christopher, and Caroline M. Hoxby. The College Admissions Project: Counselor Report. Cambridge, MA: The College Admissions Project, 2000.

Avery, Christopher, and Caroline M. Hoxby. "Do and Should Financial Aid Packages Affect Students' College Choices?" in Caroline M. Hoxby, ed. College Choice: The Economics of Where to Go, When to Go, and How to Pay for It. Chicago: University of Chicago Press, 2004.

David, Herbert. The Method of Paired Comparisons. Oxford: Oxford University Press, 1988.

Ehrenberg, Ronald G., and James W. Monks. "The Impact of US News and World Report College Rankings on Admissions Outcomes and Pricing Decisions at Selective Private Institutions." National Bureau of Economic Research Working Paper Number 7227, 1999.

Elo, Arpad E. The Rating of Chessplayers, Past and Present. London: Batsford, 1978.

Glickman, Mark E. "Paired Comparison Models with Time Varying Parameters," Doctoral thesis, Harvard University Dept of Statistics, 1993.

Glickman, Mark E. "Parameter Estimation in Large Dynamic Paired Comparison Experiments." Applied Statistics, 48 (1999), pp. 377-394.

Glickman, Mark E. "Dynamic Paired Comparison Models with Stochastic Variances," Journal of Applied Statistics, 28 (2001), pp. 673-689.

Good, Irving J. "On the Marking of Chess Players," Mathematical Gazette, 39 (1955), pp. 292-296.

Long, Bridget T. "Does the Format of a Financial Aid Program Matter? The Effect of State In-Kind Tuition Subsidies," National Bureau of Economic Research Working Paper Number 9720, 2003.

Luce, R. Duncan. Individual Choice Behavior. Wiley: New York, 1959.

Thurstone, L.L. "A Law of Comparative Judgment," Psychological Review, 34 (1927), pp. 273-286. 
Manski, Charles F., and David A. Wise. College Choice in America. Cambridge: Harvard University Press, 1983.

Mosteller, Frederick. "Remarks on the Method of Paired Comparisons. I. The Least Squares Solution Assuming Equal Standard Deviations and Equal Correlations," Psychometrika, 16 (1951), pp. 3-9.

Spence, Michael. "Education as a Signal," Chapter 2 in Market Signaling. Cambridge: Harvard University Press, 1974.

Spiegelhalter, DJ, A. Thomas, N.G. Best, and W.R. Gilks WR. BUGS: Bayesian Inference Using Gibbs Sampling, version 0.6, 1996.

Stern, Hal. "Are All Linear Paired Comparison Models Empirically Equivalent?" Mathematical Social Sciences, 23 (1992), pp. 103-117.

Toor, Rachel. "Pushy Parents and Other Tales of the Admissions Game," Chronicle of Higher Education, October 6 2000, p. B18.

Wall Street Journal. "Glass Floor: How Colleges Reject the Top Applicants and Boost Their Status," Wall Street Journal, May 29, 2001.

Zermelo, Ernst. "Die Berechnung der Turnier-Ergebnisse als ein Maximumproblem der Wahrscheinlichkeitsrechnung," Math. Zeit., 29 (1929), pp. 436-460. 